\title{
The NF1 somatic mutational landscape in sporadic human cancers
}

\author{
Charlotte Philpott, Hannah Tovell, lan M. Frayling, David N. Cooper and Meena Upadhyaya*
}

\begin{abstract}
Background: Neurofibromatosis type 1 (NF1: Online Mendelian Inheritance in Man (OMIM) \#162200) is an autosomal dominantly inherited tumour predisposition syndrome. Heritable constitutional mutations in the NF1 gene result in dysregulation of the RAS/MAPK pathway and are causative of NF1. The major known function of the NF1 gene product neurofibromin is to downregulate RAS. NF1 exhibits variable clinical expression and is characterized by benign cutaneous lesions including neurofibromas and café-au-lait macules, as well as a predisposition to various types of malignancy, such as breast cancer and leukaemia. However, acquired somatic mutations in NF1 are also found in a wide variety of malignant neoplasms that are not associated with NF1.

Main body: Capitalizing upon the availability of next-generation sequencing data from cancer genomes and exomes, we review current knowledge of somatic NF1 mutations in a wide variety of tumours occurring at a number of different sites: breast, colorectum, urothelium, lung, ovary, skin, brain and neuroendocrine tissues, as well as leukaemias, in an attempt to understand their broader role and significance, and with a view ultimately to exploiting this in a diagnostic and therapeutic context.

Conclusion: As neurofibromin activity is a key to regulating the RAS/MAPK pathway, NF1 mutations are important in the acquisition of drug resistance, to BRAF, EGFR inhibitors, tamoxifen and retinoic acid in melanoma, lung and breast cancers and neuroblastoma. Other curiosities are observed, such as a high rate of somatic NF1 mutation in cutaneous melanoma, lung cancer, ovarian carcinoma and glioblastoma which are not usually associated with neurofibromatosis type 1. Somatic NF1 mutations may be critical drivers in multiple cancers. The mutational landscape of somatic NF1 mutations should provide novel insights into our understanding of the pathophysiology of cancer. The identification of high frequency of somatic NF1 mutations in sporadic tumours indicates that neurofibromin is likely to play a critical role in development, far beyond that evident in the tumour predisposition syndrome NF1.
\end{abstract}

Keywords: NF1, Sporadic tumours, Somatic mutations, Cancer, Melanoma, Lung cancers, Glioblastoma, Leukaemia, Breast cancer, Phaeochromocytoma

\section{Background}

Neurofibromatosis type 1 (NF1: Online Mendelian Inheritance in Man (OMIM) \#162200) is an autosomal dominantly inherited tumour predisposition syndrome. Affecting 1/3000-4000 individuals worldwide, it results from constitutional mutations of the NF1 gene, lolcated on the long arm of human chromosome 17 [1-4]. A variety of characteristic clinical features are associated with NF1, including hyperpigmentary abnormalities of the skin (café-au-lait macules (CALMs) and inguinal/axillary freckling, iris hamartomas (Lisch nodules) and the

\footnotetext{
* Correspondence: Upadhyaya@cardiff.ac.uk

Division of Cancer and Genetics, Institute of Medical Genetics, Cardiff University, Heath Park, Cardiff CF14 4XN, UK

growth of benign peripheral nerve sheath tumours (neurofibromas) in the skin. Neurofibromas can be divided into several different subtypes and are associated with a variety of clinical complications. Cutaneous neurofibromas are small, discrete dermal tumours observed in most, but not all, adult NF1 patients [5]. The generally much larger plexiform neurofibromas (PNFs), a more diffuse tumour type, are present in $30-50 \%$ of NF1 patients. Importantly, some $10-15 \%$ of these benign PNFs subsequently develop into aggressive malignant peripheral nerve sheath tumours (MPNSTs) which are the main cause of morbidity in NF1 [6-8]. A number of other tumours are also associated with NF1, including optic gliomas, juvenile myelomonocytic leukaemia (JMML), benign 
or malignant phaeochromocytomas, gastrointestinal stromal tumours, glomus tumours, juvenile xanthogranulomas, rhabdomyosarcomas and lipomas.

NF1 is a tumour suppressor gene; in order for a particular cell to become cancerous, both alleles of a tumour suppressor gene must be mutated. This concept, known as the 'two-hit' hypothesis, was first proposed by Knudson, and the majority of NF1-associated tumours exhibit biallelic inactivation of NF1 $[9,10]$.

The NF1 gene is spread over a large locus (350 kbp) at 17q11.2. It contains 61 exons, including four alternatively spliced exons, and is transcribed into a $12 \mathrm{kbp}$ messenger RNA (mRNA) containing an open reading frame of 8454 nucleotides [11]. Curiously, intron 27b, the largest intron of $N F 1$ at $61 \mathrm{kbp}$, contains three embedded genes, OMGP, EVI $2 B$ and EVI2A, that are all transcribed in the opposite orientation to NF1 but whose protein products appear to have little or no interaction with neurofibromin [11].

\section{Neurofibromin: the NF1 gene product}

Neurofibromin is a 2818 amino acid, multidomain protein. Although ubiquitously expressed, its highest levels are to be found in cells of the central nervous system (CNS), where it is often found in association with tubulin. Neurofibromin is a member of a large family of evolutionarily conserved proteins: the mammalian RasGTPase-activating protein (GAP)-related proteins, and its most highly conserved region is the centrally located GAP-related domain (GRD), which is encoded by exons 20-27a. The best understood function of neurofibromin is its role in tightly regulating cellular levels of activated RAS proteins. All RAS proteins exist in two cellular states, the majority being found in their inactive GDPbound form, with only a very small fraction present in their metabolically active GTP-bound form. Only in their GTP-bound form are RAS proteins able to upregulate the many downstream effector proteins that form part of the RAS/RAF/MAPK signalling pathway [12-16]. The key role of neurofibromin is to downregulate the activated GTP-bound RAS by stimulating the low intrinsic GTPase activity of the RAS proteins themselves, thereby promoting the conversion of active RAS-GTP into its inactive RAS-GDP state. Hence, any loss of neurofibromin functionality, due to inactivating mutations in NF1, will result in sustained intracellular levels of active RASGTP, resulting in prolonged activation of the RAS/RAF/ MAPK signalling pathway and ultimately a loss of growth control and increased cellular proliferation.

Increased active RAS-GTP levels also stimulate the $\mathrm{PI} 3 \mathrm{~K} / \mathrm{AKT} / \mathrm{mTOR}$ signalling pathway which protects cells from apoptosis. In the absence of functional neurofibromin, the pathway can become constitutively activated resulting in an increase in cell proliferation and survival. The RAF/MAPK and PI3K/AKT pathways both activate mTOR signalling, a process found to be highly regulated in neurofibromas whereby mTOR pathway activation occurs in the absence of growth factors, in both NF1 tumours and neurofibromin-deficient cultured cells. Indeed, the mTOR pathway is constitutively activated in neurofibromin-deficient primary cells and tumours, and is regulated by phosphorylation and inactivation of the TSC2-encoded protein tuberin by AKT, ERK and RSK $[13,17]$. It has also been suggested that increased RAS activity in brain cells may be associated with NF1related learning deficiencies; it may result in long-term impairment as a result of increased GABA-mediated inhibition [18]. Neurofibromin levels and therefore Ras signalling can also be affected by mechanisms other than NF1 mutation including ubiquitination [19].

Neurofibromin is known to associate with a large number of proteins, including tubulin, kinesin, protein kinases A and $\mathrm{C}$, syndecan, caveolin, cytokeratin intermediate filaments and the amyloid precursor protein, although the biological significance of these protein-protein interactions is largely unknown. The diversity of protein associations does however emphasize the point that neurofibromin is likely to have many functions other than merely functioning as a GAP protein $[14,20]$. Nonetheless, to date, only the function of the GAP-related domain of neurofibromin is fully understood, so it is to be hoped that new molecular studies will reveal additional functional properties of neurofibromin [21].

\section{Mutation analysis of the NF1 gene}

The germline mutation rate of NF1 is some 10-fold higher than that observed for most other inherited disease genes, with more than half of NF1 cases attributed to de novo mutations [7]. Currently, over 2600 different inherited mutations in NF1 have been reported in the Human Gene Mutation Database (HGMD ${ }^{\circ}$ ) as a cause of NF1, varying in size from large genomic deletions spanning several megabases to single base-pair substitutions that alter an encoded amino acid or the function of a splice site [22-26]. There is, however, no evidence of any localized mutation clustering within NF1. Whilst the constitutional NF1 mutational spectrum is well defined with missense/nonsense (27.7\%), splicing (16.3\%), microdeletions (26.9\%), microinsertions (11.1\%), indels (2.0\%), gross deletions (>20 bp; 13.3\%), gross insertions (>20 bp; $2.0 \%)$, complex rearrangements $(0.6 \%)$ and a couple of putative regulatory mutations, there is no evidence of any localized mutation clustering within $N F 1$ [27, 28]. The majority $(>80 \%)$ of constitutional NF1 mutations are inactivating, predicted to result in almost complete absence of the transcript or protein [25]. Approximately $5-10 \%$ of all heritable NF1 mutations involve gross DNA alterations, mainly genomic deletions spanning the 
whole gene and flanking region, as well as intragenic multi-exon rearrangements [29]. Constitutional mutations have not been identified in any of the four alternatively spliced exons in research studies, but this may be due to ascertainment bias, as the majority of clinical laboratories that analyse NF1 do not screen these alternative exons for mutations.

A subset of the many NF1 splicing mutations, i.e. deep intronic mutations, result in the creation of novel acceptor/donor splice sites. These may give rise to the inclusion of a novel cryptic exon into the transcribed mRNA, leading to the production of an aberrant neurofibromin protein. Such mutations account for $\sim 2 \%$ of all reported constitutional NF1 mutations [30].

To date, only three NF1 families with gonadal or germline mosaicism have been reported [31-33]. In such families, only a small proportion of the germ cells, whether sperm or ova, will carry the new NF1 mutation, but this can nevertheless result in more than one affected child being produced by clinically normal parents [34].

A major challenge for clinicians and geneticists dealing with NF1 is the successful identification and characterization of causative NF1 mutations in their patients. This problem relates to a number of features of the NF1, including its large genomic size $(\sim 350 \mathrm{kbp})$ and complexity (61 exons), the absence of any obvious mutational hotspots or recurrent mutations, and the wide spectrum of mutation types observed. Indeed, the lack of mutational clustering and the paucity of recurrent mutations necessitates analysis of the entire NF1 gene in the search for potential pathogenic mutations. Furthermore, given the broad spectrum of known NF1 mutations, no single mutation detection test can, as yet, successfully identify all such mutation types [35]. Furthermore, some $30 \%$ of all NF1 mutations are predicted to cause aberrant splicing, and for this reason, the analysis of both RNA and DNA from patients in mutation screening protocols is clearly required [25]. Whilst the majority of NF1 splicing mutations occur within consensus acceptor and donor splice site sequences, a number of missense, nonsense, and even 'silent' mutations may also result in aberrant splicing, which are often only identifiable by screening a patient's RNA [25]. As well as the challenges in collection and analysis of patient mRNA, a frequent issue is the difficulty in interpreting the clinical diagnostic significance of putative NF1 missense mutations, as this may require a family segregation study and/or in vitro functional analysis to determine the pathogenicity (or otherwise) of the variant in question $[25,36]$.

Furthermore, many highly homologous NF1 pseudogene sequences are scattered throughout the human genome and can often interfere with PCR-based diagnostic tests. This emphasizes the need for the careful selection of PCR primers to avoid non-specific amplification of these pseudogene sequences.

The spatial distribution of NF1 microdeletions is strongly influenced by the presence of a number of lowcopy repeats (LCRs) spanning the $17 \mathrm{q} 11.2$ region that encompasses the NF1 gene. Indeed, studies into NF1 microdeletions have provided a general model to understand the different mutational mechanisms underlying large genomic rearrangements associated with inherited diseases [37].

The NF1 mutation detection rate in classical NF1 patients can be up to $95 \%$. However, somatic mutation detection is more challenging, largely because of the cellular heterogeneity which is characteristic of tumour tissue [38]. Mutations in multiple genes encoding the components of the RAS/MAPK pathway predispose patients to develop clinical features that overlap with those of NF1, e.g. Legius syndrome, Noonan syndrome inter alia, and the majority of these conditions are associated with tumours [39].

\section{Tumour biology}

All cancers originate from a single cell that starts to behave abnormally due to acquired somatic mutations in its genome. These somatic mutations may be the consequence of impaired DNA replication machinery, exogenous or endogenous mutagen exposures, enzymatic modification of DNA or defective DNA repair.

A subset of these somatic changes, termed 'driver mutations', confer a selective growth advantage and are implicated in cancer development, whereas the remainder are considered to be 'passengers' [40]. The Cancer Genome Atlas (TCGA), International Cancer Genome Consortium (ICGC), Catalogue of Somatic Mutations in Cancer (COSMIC) and cBioPortal for Cancer Genomics collectively represent the results of large-scale sequencing of cancers, thereby capturing many of the genomic alterations driving malignancy [41-44]. The cBio Cancer Genomics Portal is an open-access resource for the interactive exploration of multidimensional cancer genomics data sets, currently providing access to data from more than 5000 tumour samples from 147 cancer studies [44-46]. It contains data on somatic NF1 mutations in different types of tumour including melanoma (desmoplastic, skin cutaneous and uveal), breast carcinoma, neuroendocrine prostate cancer, glioblastoma, lung adenocarcinoma and squamous cell carcinoma, urothelial carcinoma, uterine carcinoma, adenoid and ovarian serous cystadenocarcinoma, paraganglioma, phaeochromocytoma, pancreatic cancer, adrenocortical carcinoma, stomach adenocarcinoma, sarcoma, oesophageal cancer, rhabdomyosarcoma and many more. In this review, we detail the frequency of somatic NF1 mutations in many non-NF1-associated sporadic cancers including melanoma, 
glioblastoma, neuroblastoma, breast cancer, ovarian serous carcinoma, paraganglioma and phaeochromocytoma, lung adenocarcinoma, lung squamous cell carcinoma, bladder, colorectal and leukaemia. Further, it is anticipated that with the advent of powerful sequencing technologies, combined with precise microdissection of tissue, somatic NF1 mutations will be identified in additional tumour types. Somatic NF1 mutations are important not only because they may be drivers but also because they may contribute to resistance to therapy [47]. Elucidation of the mutational landscape of somatic NF1 mutations in a large number of sporadic tumours, their role in the initiation and progression of tumours and how they can confer resistance or sensitivity to a therapeutic intervention may provide further insight into the mechanisms underlying tumour development and ultimately aid the development and targeting of therapies.

The frequency of somatic NF1 mutations in different sporadic tumour types derived from the literature is given in Table 1. The cBioPortal for Cancer Genomics provides a web resource for exploring, visualizing and analysing multidimensional cancer genomics data and provides graphical summaries of gene-level data from multiple platforms, shown in Fig. 1 [45].

\section{Main body}

\section{Melanoma}

Melanoma is a skin cancer that arises from melanocytes. Although the precise causes of melanomas are still not fully understood, environmental exposure to ultraviolet (UV) radiation from sunlight or tanning lamps certainly increases

Table 1 Frequency of somatic NF1 mutations in different human neoplasms

\begin{tabular}{lll}
\hline Neoplasm & $\begin{array}{l}\text { Frequency of somatic } \\
\text { NF1 mutations }\end{array}$ & References \\
\hline Cutaneous melanoma & $12-30 \%$ & {$[49-51,58]$} \\
Desmoplastic melanoma & $45-90 \%$ & {$[60,61]$} \\
Lung adenocarcinoma & $7-11.8 \%$ & {$[65-67,166$,} \\
& & $176,177]$ \\
Lung squamous cell carcinoma & $10.3-11 \%$ & {$[72,177]$} \\
Acute myeloid leukaemia & $3.5-23.6 \%$ & {$[82-85]$} \\
$\begin{array}{l}\text { T cell acute lymphoblastic } \\
\text { leukaemia }\end{array}$ & $3 \%$ & {$[88]$} \\
Breast cancer & $2.5-27.7 \%$ & {$[106,177]$} \\
Ovarian carcinoma & $12-34.4 \%$ & {$[113,115,170$,} \\
& & $177-180]$ \\
Paraganglioma/ & $21-26 \%$ & {$[121,124,177]$} \\
phaeochromocytoma & & {$[130]$} \\
Neuroblastoma & $2.2-6 \%$ & {$[132,134,177]$} \\
Glioblastoma & $14-23 \%$ & {$[143,177]$} \\
Colon adenocarcinoma & $3.8-6.25 \%$ & {$[149,167,177]$} \\
Bladder transitional cell & $6-14 \%$ & \\
carcinoma & & \\
\hline
\end{tabular}

the risk of developing melanoma. Although NF1 is associated with pigmentary abnormalities such as CALMs, malignant melanoma is not a tumour type associated with NF1.

Somatic mutation analysis of melanoma by nextgeneration sequencing has been performed at multiple centres leading to the identification of several different pathways thought to be involved in the initiation and progression of melanoma.

The direct involvement of NF1 in melanoma was first reported by Andersen and colleagues in 1993 who identified a homozygous NF1 deletion in one of eight malignant melanoma cell lines which resulted in the loss of detectable NF1 mRNA and neurofibromin protein [48]. Furthermore, the apparent absence of neurofibromin and NF1 mRNA was recorded in a primary melanoma. This led to their proposal that NF1 may function as a tumour suppressor gene in the development or progression of malignant melanoma. Many subsequent studies have identified additional somatic NF1 mutations in melanoma in $12-30 \%$ of cases [45, 49-55].

RAS/MAPK pathway dysregulation has been identified as a key culprit in non-familial melanoma, leading to the discovery of $B R A F$ and NRAS as the most commonly mutated genes [56]. Indeed, $B R A F$ mutations occur in $50-70 \%$ of all cutaneous malignant melanomas, whilst NRAS alterations only occur in $19-28 \%$ of tumours. In both cases, these gene lesions result in constitutive activation of the MAPK pathway and are believed to be early somatic events associated with melanoma initiation [56, 57]. The high frequency of BRAF and NRAS mutations in melanomas has recently been confirmed by high-throughput next-generation sequencing (NGS) analysis which also identified additional driver mutations, including a recurrent $R A C$ mutation, which is the third most frequent activating mutation in sun-exposed melanomas after BRAF and NRAS mutations [50,51].

Inactivating NF1 mutations have been detected in approximately $13 \%$ of melanomas, alongside mutations in other tumour suppressor genes, including TP53, ARID2, PTEN, CDKN2A, MAP2K1 and RB1 [51]. The impact on $N R A S$ is however non-uniform, with some NF1 mutant melanomas exhibiting full $N R A S$ activation (i.e. the same activation level as oncogenic NRAS mutations), whereas others exhibit only partial activation [51]. In a mouse melanoma model, NF1 mutations cooperate with BRAF mutations in the pathogenesis of melanoma by preventing oncogene-induced senescence, an indication that NF1 plays a key role in early melanoma development [58]. In both mouse tumour models and A375 human melanoma cell lines, Maertens and colleagues have shown that resistance to treatment was enhanced by further suppression of NF1 by small hairpin RNA (shRNA). Furthermore, they observed that resistance to the BRAF inhibitor PLX4720 was attenuated by reconstitution of 


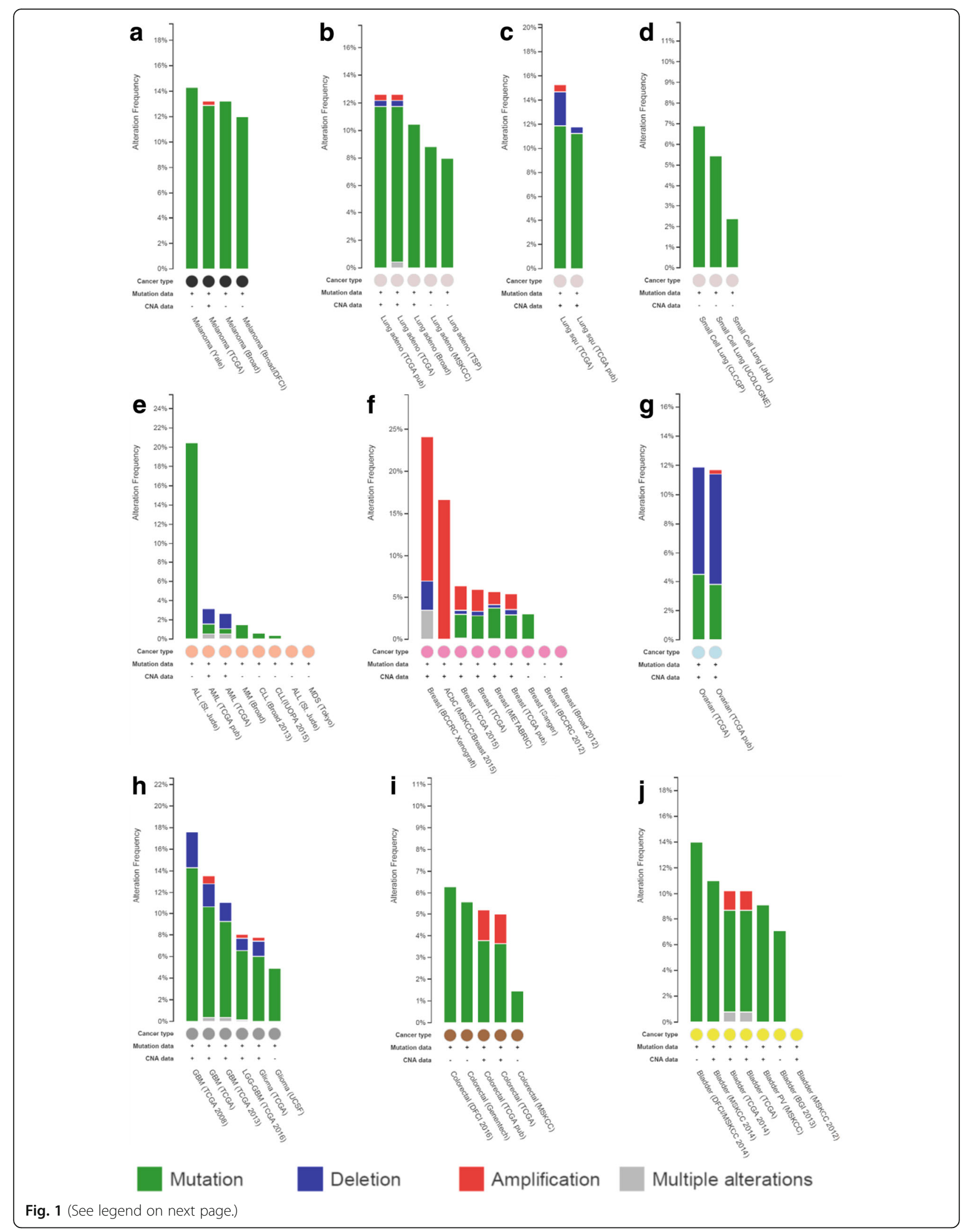


(See figure on previous page.)

Fig. 1 The frequency and nature of somatic NF1 mutations in different cancer types derived from the cBio dataset. a Malignant melanoma. b Lung adenocarcinoma. c Lung squamous cell carcinoma. d Small cell lung carcinoma. e Acute lymphocytic leukaemia (ALL). Acute myeloid leukaemia (AML), chronic lymphocytic leukaemia (CLL), malignant myeloma (MM) and myelodysplastic syndrome (MDS). f Breast carcinoma. g Serous ovarian carcinoma. h Brain glioma, including glioblastoma multiforme $(G B M)$. i Colorectal carcinoma. $\mathbf{j}$ Bladder transitional cell carcinoma. Mutations = single base-pair substitutions, in-frame microdeletions/insertions, frameshift microdeletions/insertions, splice site mutations (including those that can create in-frame deletions via exon skipping), nonsense mutations and frameshift insertions/deletions (shown in green); deletions = gross, multi-exonic and whole gene deletion identified as copy number changes (shown in blue); amplification = multi-exonic, whole gene duplications identified as copy number changes (shown in red); multiple alterations = some combination of mutations, deletions and/or amplification (shown in grey) [44-46]

NF1 in these cells [58]. Using RNA interference (RNAi) screening techniques, Whittaker and colleagues confirmed that NF1 mutation is a key mechanism in BRAF inhibitor resistance. An RNAi screen, targeting more than 16,500 genes in a BRAF inhibitor-sensitive melanoma cell line, identified NF1 as the highest ranking protein affected by BRAF inhibition, and that, NF1 knockdown abrogated the growth inhibitory effects of BRAF inhibition [53]. Indeed, it was found that NF1 suppression led to a 31 -fold increase in resistance to PLX4720, as well as a partial (7-fold) resistance to MEK inhibition, demonstrating that human melanoma samples with innate resistance to BRAF inhibition and sensitivity to a MEK inhibitor harboured NF1 mutations [53].

Importantly, $N F 1$ mutations have been found in melanomas that lack both $B R A F$ and NRAS mutations, with $25-30 \%$ of such melanomas found to harbour deleterious NF1 mutations, thus implying that NF1 inactivation has conferred aberrant MAPK pathway activation in these tumours [50,51]. BRAF/NRAS wild-type and NF1 mutant melanomas are strongly associated with UV damage, as evidenced clinically by the higher degree of solar elastosis and, at a molecular level, by a high proportion of $\mathrm{C}>\mathrm{T}$ transitions at pyrimidine dimers and more frequent tandem CC $>$ TT transitions [59].

A recent study based on 213 human melanoma samples identified three frequently mutated genes: $B R A F$, $N R A S$ and NF1, with frequencies of 38.5, 28.6 and $12.2 \%$, respectively [49]. Whilst known recurrent activating mutations were identified in $B R A F$ and $N R A S$, a high number of inactivating mutations were identified in NF1. Notably, almost half $(26 / 56)$ of BRAF and NRAS wild-type melanomas had an NF1 mutation, most identified by loss of heterozygosity (LOH). Furthermore, NF1 mutation-containing melanomas also harboured significantly more somatic mutations across all loci and occurred in significantly older patients, although they were associated with similar overall patient survival rates as compared to BRAF or RAS mutant or BRAF-RAS-NF1 wild-type melanoma. In addition, all $26 N F 1$ mutant $B R A F-R A S$ wild-type melanomas carried mutations in other known RASopathy genes, including RASA2, PTPN11, SOS1, RAF1 and SPRED1 [49]. In contrast to Whittaker and colleagues, Krauthammer et al. also found that $6 / 10$ NF1 mutant cell lines were highly sensitive to a MEK inhibitor, whereas the other four were highly resistant, clearly indicating that NF1 suppression is not always associated with either sensitivity or resistance to MEK inhibitor $[49,53]$.

\section{Desmoplastic melanoma}

The highest frequency of somatic NF1 mutations were found in desmoplastic melanomas (14/15) [60]. These melanomas are characterized by their higher propensity for local recurrence and less frequent metastatic spread to regional lymph nodes. The high frequency of NF1 mutations in desmoplastic melanomas appears to indicate an important role for neurofibromin in the specific biology of this type of melanoma. Another recent study screened 20 desmoplastic melanomas by exome sequencing for alterations in the MAPK and PI3K signalling pathways, i.e. mutations in $C B L, E R B B 2, M A P 2 K 1, M A P 3 K 1, B R A F$, EGFR, PTPN11, MET, RAC1, SOS2, NRAS and PIK3C, which were found in 15/20 (75\%), with NF1 mutations being found in $9 / 20(45 \%)$ [61].

\section{Uveal melanoma}

Melanoma of the uveal tract (i.e. iris, ciliary body and choroid) is rarer than cutaneous melanoma but is nevertheless the most common primary intraocular malignancy in adults, with inactivating mutations found in approximately $60 \%(23 / 38)$ of uveal melanomas [62]. Intriguingly, whilst not malignant, the Lisch nodules characteristic of NF1 is hamartomatous uveal melanocytic proliferations of the iris.

\section{Mucosal melanoma}

Mucosal melanoma differs from cutaneous melanoma in terms of its molecular profile, with less frequent $B R A F$ and more frequent KIT mutations but also has a poor prognosis. In a recent study [63] of a cohort of $75 \mathrm{tu}$ mours from patients with a mucosal melanoma, NF1 and RAS mutations were identified in 18.3 and $16.9 \%$ samples, respectively, whereas 8.4 and $7 \%$ of tumour samples harboured BRAF and KIT mutations [63]. This study demonstrates that NF1 is the most frequently occurring driver mutation in mucosal melanoma. 


\section{Lung cancer}

Lung cancer is responsible for about $10 \%$ of all cancer cases worldwide; the vast majority of which has been attributed to tobacco smoking [64]. The two main types are non-small cell lung cancer (NSCLC) in 80-90\% cases and small cell lung cancer (SCLC) found in 10$15 \%$ of patients. NSCLC has multiple subtypes, including adenocarcinoma (ADC), squamous cell carcinoma $(\mathrm{SqCC})$ and undifferentiated (large cell) lung carcinoma.

\section{Adenocarcinoma}

Approximately $40 \%$ of NSCLC are ADC, and several studies have reported somatic NF1 mutations in some $7-11 \%$ of ADC [65-68]. The high mortality rate characteristic of this tumour type is due in part to the frequent presentation of such tumours at a locally advanced or metastatic stage and the lack of an effective advanced stage treatment $[65,69]$. A number of potential novel therapeutic targets have been identified, including the activating mutations in $K R A S, B R A F, E R B B 2$ and PIK3CA; the translocations in RET and ROS1; and the loss of function or deletions of TP53, NF1, CDKN2A and KEAP1 [65, 70]. Whilst NF1 mutations were only found in 7\% (13/188) of sporadic lung ADC [65], further analysis found that biallelic inactivation at the NF1 locus may be present in as many as $23 \%$ (3/13), although it is not known whether these lesions occurred in cis or in trans [65]. Similarly, Imielinski et al. identified somatic NF1 mutations in 10.9\% (20/183) of lung ADC, of which half were found to be truncating mutations, resulting in a complete loss of function [66].

In addition to NF1 being recurrently mutated in a subset of sporadic lung ADC patients, the MAPK pathway also appears to be an important regulatory pathway involved in tumorigenesis [65]. The TCGA research network examined the genomes, RNA and some protein from 230 previously untreated lung ADC and matched normal samples $[41,67]$. In three quarters of the samples, the group identified mutations in NF1 and other genes that activate the RTK/RAS/RAF cell signalling pathway. This study not only identified loss-of-function NF1 defects but also demonstrated that NF1 mutations (as well as KEAP1 and TP53 mutations) are far more frequent in the BRAF-RAS oncogene-negative subset of lung ADC. Additionally, TCGA and other groups have identified genes such as TP53, KRAS, STK11 (LKB1), EGFR and NF1 to be significantly mutated in ADC [67].

Markedly reduced NF1 mRNA expression in ADC has been found to confer both an intrinsic and an acquired resistance to EGFR inhibitors [71]. By performing a genome-wide siRNA screen of both a human lung cancer cell line and a murine mutant EGFR-driven lung ADC, this revealed reduced NF1 mRNA expression in both, and furthermore, whilst the EGFR inhibitor erlotinib failed to fully inhibit RAS-ERK signalling when neurofibromin levels were reduced, treatment of neurofibromin-deficient lung cancers with MEK inhibitor restored sensitivity to erlotinib [71].

In a recent study of 591 NSCLC, 60 had NF1 mutations (10\%) whilst 141 (24\%) harboured KRAS mutations [68]. Approximately $25 \%$ of the NF1 mutations cooccurred with mutations in known oncogenes: $B R A F$, $E R B B 2, K R A S, H R A S$ and NRAS. Therapeutic strategies targeting $K R A S$ activation, including the use of inhibitors of MAP kinase signalling, may warrant investigation in NF1 mutant tumours. Additional tumour suppressor inactivation pattern studies may help to inform novel treatment strategies.

\section{Squamous cell carcinoma}

According to the TCGA, somatic NF1 changes are present in approximately $12 \%$ of squamous cell lung cancers (SqCC), of which four distinct subtypes have been identified: classical, primitive, basal and secretory expression [72]. The basal expression subtype was found to harbour NF1 alterations, suggesting a potential direction for the treatment of such tumours. The information from the TCGA studies has highlighted the involvement of NF1 in both lung ADC and SqCC and served to improve our understanding of the genetic pathways that lead to lung cancer [72].

Transcriptome analysis of 153 tumour samples, including ADC, SqCC, large cell lung cancer, adenoid cystic carcinomas and derived cell lines, has been integrated with the data from The Cancer Genome Atlas and other published sources [73]. This confirms the previously reported CD74-NRG1 fusion and also suggests that the NRG1, NF1 and Hippo pathway fusions may play important roles in tumours without known driver mutations and that this prognostic factor may be associated with poor survival [73]. Several different gene fusions, viz. NF1-GOSR1, NF1-PSMD11, NF1-NLK, NF1-DRG2 and NF1-MYO15A, were also detected by transcriptome sequencing of lung cancers [73]. Interestingly, both lung $\mathrm{ADC}$ and $\mathrm{SqCC} \mathrm{DNA}$ displayed a significantly increased frequency of guanine (cytosine) to thymine (adenine) mutations, a type of mutation associated with exposure to tobacco smoke [68]. Lung ADC genomes also manifest regional heterogeneity in terms of the distribution of mutations with sequencing data from lung cancer studies clearly indicating that lung cancer, at the molecular level, is a highly heterogeneous disease. Indeed, the mutational landscape of lung ADC is substantially different from that of SqCC of the lung or SCLC [74], with frequent receptor tyrosine kinase mutations found in lung $\mathrm{ADC}$, that are rarely encountered in either SqCC or SCLC [75]. 
Mutations in TP53, KRAS, LKB1, NF1 and RBM10 are enriched in transversion-high tumours, whilst mutations in EGFR, RB1 and PIK3CA and in-frame insertions in the receptor tyrosine kinases $E G F R$ and $E R B B 2$ are enriched in transversion-low tumours [75]. The transversion-high group was found to be strongly associated with past or present smoking $\left(P<2.2 \times 10^{-16}\right)[72,74,75]$.

To compare lung ADC and SqCC and to identify new drivers of lung carcinogenesis, Campbell and colleagues examined the exome sequences and copy number profiles of 660 lung ADC and 484 lung SqCC tumour normal pairs [74]. They observed median somatic mutation rates of 8.7 mutations/Mbp and 9.7 mutations/Mbp for lung $\mathrm{ADC}$ and $\mathrm{SqCC}$, respectively. At least 38 genes were significantly mutated in lung $A D C$ and 20 genes in SqCC; however, only six genes, TP53, RB1, ARIDIA, CDKN2A, PIK3CA and NF1, were significantly mutated in both tumour types, and of these, TP53, CDKN2A and PIK3CA mutations had a significantly higher frequency in lung SqCC. Recurrent alterations in lung SqCC were more similar to those of other squamous carcinomas than to alterations in lung ADCs, whilst the significantly mutated genes in lung ADC were most similar to those associated with glioblastoma and colorectal cancer.

\section{Small cell lung cancer}

Although there is a paucity of data for small cell lung cancer (SCLC), the frequency of NF1 mutations in SCLC was found to be 2.4 and $6.9 \%$ in two independent studies [76, 77]. In a subsequent study of 98 SCLC, DNA was sequenced to a high, uniform coverage and analysed for all classes of genomic alterations [78]. Of the seven most commonly altered genes identified, only one (RICTOR) was considered to be actionable in terms of treatment. The most common non-actionable genomic alterations were found in TP53 (86\% of SCLC cases), RB1 (54\%) and MLL2 (17\%), with NF1 mutations identified in only $3 \%$ of SCLC, consistent with the earlier studies.

\section{Myeloid malignancies}

Myeloid malignancies are clonal disorders characterized by acquired somatic mutations in various haematopoietic progenitors. Constitutional NF1 mutations are known to predispose individuals to myeloid malignancies such as chronic myelomonocytic leukaemia (CMML), JMML and acute myeloid leukaemia (AML) [79]. Somatic 17q11 deletions encompassing NF1 have been described in many adult myeloid malignancies [80]. More generally, the RAS signalling pathway has been found to be fundamental in the development of myeloid malignancies, with somatic activating mutations in NRAS and KRAS genes estimated to be present in 20 to $40 \%$ of diagnosed cases of AML, CMML and JMML [81]. Recent advances in understanding the genetic basis of myeloid malignancies have provided important insights into the pathogenesis of AML. Whilst somatic KRAS and NRAS mutations are frequently found in AML, mutations in other RAS signalling pathway genes, including $N F 1$, occur at lower frequencies, although the reported frequency for NF1 somatic mutations ranges quite widely from 3.5 to $23.6 \%$ [79, 82-85].

Parkin and colleagues identified NF1 mutations in 7\% of cases with AML, with a further $12 \%$ displaying copy number alterations (CNAs) involving NF1, mainly heterozygous deletions [85]. The absence of NF1 expression was observed in 7\% of adult AML associated with an increased RAS-GTP level. In another study of AML with CBHB-MYHII rearrangements, $16 \%$ of the samples harboured NF1 deletions [84]. However, high-resolution studies have failed to provide any evidence for frequent NF1 alterations in de novo AML, although they suggested that NF1 mutations may contribute to tumour progression [82]. In this study, the authors screened a total of 488 previously untreated de novo AML patients for the NF1 deletion using either array comparative genomic hybridization $(\mathrm{aCGH})$ or real-time quantitative $\mathrm{PCR} /$ fluorescence in situ hybridization approaches. Using aCGH, a small $~ 0.3 \mathrm{Mbp}$ minimally deleted region involving NF1 was defined; the overall frequency of NF1 deletion was 3.5\% (17/485). Furthermore, NF1 deletion was significantly associated with abnormal cytogenetics and a monosomal karyotype, whilst only one of five NF1-deleted patients acquired a coding mutation in the remaining allele. This study indicates that NF1 microlesions are infrequent in de novo AML and may be secondary events in leukemic progression.

\section{Myelodysplastic syndrome}

The frequency of NF1 changes in myelodysplastic syndrome has been found to vary between 0 and $9 \%$ $[86,87]$.

\section{$T$ cell acute lymphoblastic leukaemia}

$\mathrm{T}$ cell acute lymphoblastic leukaemia (T-ALL) is a variant of acute lymphoblastic leukaemia (ALL), with features similar to some types of lymphoma. It accounts for about 15 and $25 \%$ of ALL in paediatric and adult cohorts, respectively.

T-ALL is a highly aggressive malignancy, characterized by rapid progression and high relapse rates [79]. Somatic mutations in a number of established T-ALL drivers such as KRAS, NRAS, PIK3CA, PTEN, NOTCH1, PHF6 and NF1 have been identified in T-ALL cell lines and patient samples [88]. Somatic NF1 mutations have been found in $27.3 \%(9 / 33)$ of the T-ALL cohort; however, only $12.1 \%(4 / 33)$ were non-synonymous mutations [88]. The type 1 NF1 microdeletion $(1.4 \mathrm{Mb})$ was reported in $2.9 \%(3 / 103)$ of T-ALL patients [79]. None of these three 
individuals with the microdeletion exhibited any clinical characteristics of NF1.

\section{Juvenile myelomonocytic leukaemia}

JMML is a myeloproliferative neoplasm (MPN) of childhood, occurring when too many immature white blood cells (myelocytes and monocytes) are made in the bone marrow. In 1997, Side and colleagues reported constitutional NF1 mutations in 15\% of JMML patients [89]. JMML generally carries a very poor prognosis, with the only curative treatment being haematopoietic stem cell transplantation.

JMML was once considered a unique example of RAS-driven oncogenesis because it was thought to be initiated by mutually exclusive mutations in the RAS genes (NRAS or KRAS) or in several RAS pathway regulators (PTPN11, NF1 or CBL) [90].

In an exploration of the somatic mutation landscape of 30 patients with syndromic $(n=8)$ or sporadic $(n=22)$ JMML, a combination of genome-wide DNA array analysis, whole-exome sequencing and targeted sequencing was used in paired germline and tumour samples [90]. In total, 85 somatically acquired genetic alterations were found in $83 \%(25 / 30)$ of patients in this sub-cohort. Genes containing somatic variants detected by whole-exome sequencing, or previously reported to be mutated in JMML, were then sequenced in the full cohort of 118 JMML cases. A total of 122 secondary clonal abnormalities, in addition to initiating RAS pathway mutations, were identified in $49 \%$ (58/118) of patients [90]. In addition, sequencing of isolated myeloid colonies demonstrated the coexistence of multiple RAS hits in the same myeloid progenitors in three of the JMML cases tested, challenging the concept of mutually exclusive RAS pathway mutations.

The polycomb recessive complex 2 (PRC2) is involved in cellular differentiation, maintenance of cell identity and proliferation as well as stem cell plasticity [91] and also drives myeloid malignancies. Nf1/Kras doublemutant mice have been shown to develop myeloid malignancies with reduced latency and increased severity in comparison to mice with only one of the two defects because copy number variations (CNVs) in Nf1/Kras mutant mice frequently resulted in haploinsufficiency for PRC2 core subunits (SUZ12 or EZH2) or PRC2associated factors necessary for optimal PRC2 activity (AEBP2, CDYL or JARID2) [92]. In addition, haploinsufficiency for multiple genes that regulate PRC2 function can cooperate in myeloid transformation, and other mutations in JMML target a small number of pathways specifically, including components of the RAS and PRC2 networks [93, 94]. Thus, RAS activation is a major player, and other pathways such as PRC2 are also important. Notably, PRC2 also plays a role in the development of MPNSTs. Loss of function of PRC2 (due to mutations in EED or SUZ12) is also found in the vast majority of sporadic, NF1-associated, and radiotherapyassociated MPNSTs (where PRC2 loss amplifies Rasdriven transcription) $[95,96]$.

In a recent study focussing on characterization of serial samples from JMML patients at diagnosis and then beyond through relapse and transformation to AML, mutations were found in NF1, NRAS, KRAS, PTPN11 or $C B L$ in $85 \%$ of patients, as well as recurrent mutations in other genes involved in signal transduction, splicing, PRC2 and transcription. The number of somatic alterations present at diagnosis appeared to be important for the outcome of JMML [97].

\section{Breast cancer}

The NF1 gene is reported to be frequently mutated in sporadic breast cancers, although in only a few studies has mutation frequency been published. NF1 patients have an increased risk of developing breast cancer as compared to the general population $[8,98]$. In particular, women under the age of 50 with NF1 have an increased (4-5-fold) risk of developing breast cancer (standardized incidence ratio for women under 50) and also a 3.5-fold increased fatality risk (proportionate mortality ratio) [98-100]. A predisposition to breast cancer in NF1 patients has led researchers to postulate the potential involvement of somatic NF1 mutations in initiating and driving the malignant transformation and progression of sporadic breast cancer. A number of breast cancer genome sequencing studies have identified NF1 as one of a number of novel, recurrently mutated genes in sporadic tumours which could potentially be targeted in a therapeutic context [101, 102].

It was Ogata and colleagues, working with established breast cancer cell lines in 2001, who first identified a role for NF1 in the malignant transformation of mammary cells [103]. Further analysis of the NF1 deletionbearing tumours revealed significantly higher levels of active RAS, indicating that RAS signal transduction pathway dysregulation, through NF1 loss, may be responsible for driving malignancy in these cells. Neurofibromin was found to be below detectable levels in the highly malignant and treatment-resistant MB-231 breast cancer cell line as compared with four other less aggressive cell lines. Additionally, the MB-231 cells exhibited a 10-fold increase in PMAPK levels as a result of activated Ras, despite there being no changes in $\mathrm{p} 120^{\mathrm{GAP}}$. Hence, this study suggested that under-expression of NF1 and reduced neurofibromin activity may have a direct influence on malignant transformation and resistance to anti-cancer agents [103]. This is consistent with other studies and goes some way towards accounting for the presence of the somatic NF1 mutations found in sporadic breast tumours. 
The mouse model Chaos3 is characterized by the spontaneous development of mammary tumours, due to a mutation in $\mathrm{Mcm} 4$ leading to chromosomal instability through disruption of the MCM2-7 complex [104, 105]. Somatic NF1 deletions were found in almost all (59/60) of the mammary tumours studied in this mouse model, and upon subsequent examination of TCGA data, it was noted that NF1 is somatically mutated or deleted in $27.7 \%$ of human breast cancers $[105,106]$.

Large-scale NGS to compare primary and recurrent breast cancer has found mutations in recurrent tumours which were not present in matched primary tissue [107]. However, the difficulties inherent in studying recurrent tumours mean that the sample size was necessarily small in this study, with only 74 matched tumours from 43 patients across the various breast cancer subtypes. So, the precise role for NF1 in breast cancer is still unclear and further studies are required.

CNAs dominate the breast cancer genome, with NF1 gene amplification being a particular feature not seen in the other tumour types in which NF1 mutations are observed (Fig. 1), suggesting that gain of neurofibromin function is especially important in breast cancer biology. In contrast, genes generally mutated in breast cancers are subject to a low frequency of somatic mutations, including single nucleotide mutations and indels in driver genes $[105,106]$.

Large-scale efforts by the TCGA and ICGC have contributed greatly towards determining the identity of genes mutated in breast cancer, but analysis of clinical associations in these data sets is limited by the scarcity of long-term patient follow-up data and the stringent criteria used for sample selection (e.g. tumour size, malignant cellularity) [41, 42].

In a recent study based on 2433 molecular profiles of breast cancer, it was noted that high levels of intratumour heterogeneity was generally associated with a worse clinical outcome, with one exception: highly aggressive breast tumours with 11q13-14 amplification had low levels of intra-tumour heterogeneity [108, 109]. Inactivating NF1 mutations were also found to be associated with breast cancer severity score in oestrogen receptor-negative tumours.

As with melanoma and neuroblastoma, inactivation of NF1 in breast cancer is associated with resistance to drug therapy. A potential mechanism for NF1 and drug resistance in breast adenocarcinoma has been suggested following analysis of the MCF-7 breast cancer cell line [110]. Silencing of NF1, amongst several other genes, has been shown to confer a tamoxifen-resistant phenotype, although it was noted that resistance- or sensitivity-specific gene expression patterns may give a better prediction of treatment outcome as compared to single genes [111]. This is potentially of great clinical importance, of course, as, although tamoxifen is one of the most widely used anti-breast cancer agents, it is now apparent that up to $\sim 40 \%$ of early-stage breast cancer patients who receive tamoxifen as an adjuvant therapy will ultimately develop tamoxifen resistance and relapse $[111,112]$.

\section{Ovarian cancer}

High-grade serous ovarian carcinoma (HGOSC) is the most common and malignant form of ovarian tumours accounting for up to $70 \%$ of all ovarian cancer cases. Some serous cancers may initiate in cells at the distal end of the fallopian tube, then spread to the ovary. There are different subtypes of epithelial ovarian cancer including mucinous, endometrioid, clear cell, undifferentiated or unclassifiable; therefore, HGOSC is a molecularly and clinically heterogeneous disease which accounts for the majority of ovarian cancer deaths.

More than a third of all ovarian serous carcinomas (OSCs) harbour somatic NF1 mutations, identifying an alternative target for treatment and an additional prognostic marker. This is of particular importance when considering the disease heterogeneity, high relapse and fatality rates $[113,114]$.

A role for NF1 in ovarian serous carcinoma (OSC) was first proposed by Sangha et al. in 2008 [113]. Genomewide microarray analysis of 36 primary OSC identified homozygous NF1 deletions in two tumours. This group subsequently screened 18 ovarian carcinoma-derived cell lines and 41 primary OSC for additional NF1 alterations, with $8 / 18$ cell lines exhibiting marked reduction or no expression of NF1. Homozygous NF1 gene deletions and NF1 splicing mutations were identified in 9/41 primary OSC. Additionally, tumours and cell lines with NF1 lesions were found to lack KRAS and BRAF mutations, whilst exhibiting Ras pathway activation [113].

The Cancer Genome Atlas project analysed the expression of mRNA and microRNA, promoter methylation and DNA copy number in 489 HGOSC and performed genomic DNA analysis in 316 tumours. Loss of NF1 function was identified in 12\% (37/316) of samples, and of these, 24 had deletions, one had a duplication and the remaining (12) samples harboured other somatic mutations. The Australian Ovarian Cancer Study (AOCS) specifically examined CNAs and reported regions of copy number loss at the NF1 locus in $34 \%$ (137/398) of ovarian cancer samples, comprising 157 serous adenocarcinomas from the TCGA cohort and a further 241 samples, of both endometrioid and serous subtypes [115].

HGOSC shows a simple mutational profile, with TP53 nearly always mutated, but with other genes, including $N F 1$, mutated at a low frequency [116]. Approximately $50 \%$ of all HGSOCs exhibit homologous recombination 
(HR) deficiency, with such tumours being highly sensitive to PARP inhibitors [117]. However, NF1 mutations identified in advanced HGOSC are associated with resistance to treatment because of the acquisition of different new mutations within the gene [116-118].

\section{Paragangliomas and phaeochromocytomas}

Phaeochromocytomas are rare tumours (annual incidence of 1-6 million per year) that develop from neural crestderived chromaffin cells and produce excess catecholamine, resulting in hypertension and flushing. Despite being rare in the general population, the frequency of occurrence amongst NF1 patients is much higher, with $0.1-6 \%$ developing a phaeochromocytoma $[119,120]$.

$N F 1$ is one of a number of known paraganglioma and phaeochromocytoma susceptibility genes, constitutional mutations in which are responsible for inherited tumour syndromes. Somatic NF1 mutations occurred in 35/161 (21.7\%) of sporadic phaeochromocytomas, with the majority exhibiting LOH and low NF1 mRNA expression [121-123], whilst somatic mutations in the susceptibility genes NF1, MAX, RET, VHL, SDHA, SDHB, SDHC, $S D H D, S D H A F 2, K I F 1 B \beta$ and TMEM127 are present in $11-19 \%$ of sporadic cases [124-126]. It has also been demonstrated that the majority $(83 \%, 35 / 42)$ of sporadic phaeochromocytomas harbour a CNA in at least one of these susceptibility genes, thereby altering respective protein expression levels [123]. This is in addition to the $26 \%(11 / 42)$ of sporadic paragangliomas and phaeochromocytomas that have lost one NF1 allele, associated with a reduction in NF1 mRNA level. Furthermore, 10 of 11 tumours were also observed to harbour a somatic protein-truncating NF1 mutation in the second allele [121]. This study also identified a correlation between NF1 mutations and a biochemical phenotype: paragangliomas and phaeochromocytomas harbouring a somatic NF1 mutation were found to display higher plasma levels of normetanephrine $(P=0.005)$ and metanephrine $(P=0.0025)$, markers for catecholamine-secreting tumours [121]. This could be of significance as plasma catecholamine levels are used in the diagnosis of phaeochromocytoma and paraganglioma; however, these findings were reported in only a small sample group and the biochemical data was non-centralized and incomplete, limiting their overall significance [123].

A large-scale analysis of a cohort of 202 paragangliomas and phaeochromocytomas, collected by the Cortico et Médullosurrénale: les Tumeurs Endocrines (COMETE) network, examined CNAs, somatic and constitutional mutations in known susceptibility genes [124]. Almost a quarter (25/119) of the sporadic phaeochromocytomas/ paragangliomas carried an inactivating NF1 mutation, of which $21 / 25$ were associated with the loss of the wildtype allele. Of all the somatic mutations identified in the study, 56\% were located in NF1, showing that NF1 is frequently mutated in phaeochromocytomas/paragangliomas [124].

\section{Neuroblastoma}

Neuroblastoma is a neuroendocrine tumour that originates from neural crest cells of the sympathetic nervous system, with most tumours developing in the abdomen. Neuroblastoma is the second most common solid tumour in childhood and accounts for $8 \%$ of all childhood cancers. The treatment for neuroblastoma includes surgery, chemotherapy, radiation and bone marrow transplantation. Familial neuroblastoma cases comprise only a small fraction $(\sim 1-2 \%)$ of all neuroblastoma cases, and their genetic aetiology is relatively well understood [127, 128]. In contrast, far less is known of the genetic aetiology of sporadic neuroblastomas, despite their accounting for the majority of cases.

It was a quarter of a century ago when NF1 was first reported to play a role in the development of neuroblastoma. In this study, 4/10 neuroblastoma cell lines were observed to express either a reduced level or a complete absence of neurofibromin, with NF1 mutations being identified in two of these cell lines [129]. Furthermore, it was demonstrated that the introduction of a normal human chromosome 17 into a neuroblastoma cell line suppressed its tumorigenicity. Several NF1-deficient neuroblastoma cell lines exhibited only moderately elevated Ras-GTP levels, in contrast to NF1 tumour cells, indicating that neurofibromin can contribute differently to the negative regulation of RAS in different cell types [130, 131].

Somatic NF1 mutations in neuroblastomas have been correlated with reduced expression of neurofibromin and poor patient prognosis, whilst higher levels of expression are associated with longer progression-free survival [130, 131]. Hölzel and colleagues also reported a loss of neurofibromin expression in $8 / 25$ neuroblastoma cell lines and that a further SNP analysis of 20 neuroblastoma cell lines detected 50\% (10/20) with abnormal NF1 alleles [130]. Genomic aberrations in NF1 were also found in primary neuroblastomas but at a lower frequency of $6 \%(5 / 83)$.

A large-scale RNAi screen revealed an association of NF1 loss in neuroblastoma cell lines with resistance to retinoic acid (RA) treatment which is used as targeted therapy in the treatment of neuroblastomas. Loss of NF1 activates RAS-MEK signalling, which in turn represses ZNF423, a critical transcriptional coactivator of the retinoic acid receptors; neuroblastomas with low levels of both NF1 and ZNF423 have an extremely poor outcome. However, inhibition of MEK signalling downstream of NF1 restores responsiveness to RA, suggesting a potential therapeutic strategy to overcome RA resistance in NF1-deficient neuroblastomas [130]. 


\section{Glioblastoma}

Glioblastomas are tumours that arise from astrocytes that comprise the supportive tissue of the brain. These tumours are usually aggressive as the cells divide rapidly and are also supported by a large network of blood vessels. The most aggressive subtype is glioblastoma multiforme (GBM) which is the most frequent form of brain cancer in adults, renowned for its lethality and poor prognosis and is thus an important target of study [132, 133].

Glioblastoma-associated NF1 somatic mutations are well described [132, 134, 135], with recurrent driver mutations being identified in NF1 and a number of other candidate genes (IDH1, TP53, CDK4, EGFR, PI3KR1, PIK3CA, PTEN, RB1 and CDNK2A) in GBM [132]. NF1 mutations were identified in at least $15 \%(16 / 105)$ of all GBM by Parsons and colleagues, although chromosomal translocations or epigenetic changes were not tested in this cohort [132].

A TCGA analysis assessed levels of gene expression, CNAs and DNA methylation in a cohort of 206 glioblastoma tumour samples, with recurrent mutations in NF1, AKT3, PRK3R1 and PARK2 being identified, and with 14\% (13/91) of samples found to contain at least one somatic NF1 mutation. Verhaak and colleagues subsequently performed large-scale genomic analysis of these TCGA data, dividing glioblastoma cases into four subtypes: proneural, neural, classical and mesenchymal [136]. They found that GBM with NF1 and PTEN alterations had a distinct mesenchymal-like expression profile, with $53 \%$ of mesenchymal cases having an NF1 mutation. The mutual exclusivity of NF1 and BRAF mutations in GBM has also been reported [134].

In animal models, inactivation of TP53 and PTEN may cooperate with NF1 loss in the development of glioblastoma [137]. Haploinsufficiency of NF1 is also reported to increase astrocyte proliferation and enhancement of angiogenesis in $\mathrm{Nf1}^{+/-}$heterozygous mouse models $[138,139]$.

\section{Colorectal cancer}

Colorectal cancer (CRC) is one of the leading causes of cancer-related deaths in the western world, with at least $50 \%$ of CRCs exhibiting dysregulation of the RAS/ MAPK pathway. Reports of the type of NF1 mutations in CRC vary widely, with NF1 LOH first reported in 14$57 \%$, and reported gains in part of, or even a complete duplication of, the NF1 gene in 17\% of CRC [140-142]. The 2012 TCGA genome-scale analysis of 212 CRC found that 24 genes were predominantly mutated, including NF1 in approximately $5.6 \%(11 / 212)$ of cases [143]. Subsequent studies have confirmed this, with NF1 mutations being identified in $5.6 \%(4 / 72)$ and $5.8 \%$ of cases (39/619), respectively [144, 145].

Several critical genes and pathways, such as WNT, RAS/MAPK, PI3K, TGF- $\beta$, P53 and DNA mismatch repair, are recognized in the initiation and progression of CRC [146, 147]. Although genetic alterations in the PI3K and RAS/MAPK pathways are common in CRC and NF1 alterations have been detected in $5-6 \%$ of cases, it remains unclear as to whether NF1 mutations in $\mathrm{CRC}$ are related to chemotherapeutic effect.

\section{Urinary tract transitional cell carcinoma}

The best documented molecular factors involved in urothelial transitional cell carcinoma (TCC) are the RAS proto-oncogene activation and TP53 mutations. Alterations in NF1 gene expression in TCC were first reported in 1999 [148], where decreased NF1 gene expression was observed in $83 \%(23 / 29)$ of TCC specimens (as estimated by immunohistochemistry), whilst NF1 mRNA levels were markedly lower in TCC tissue as compared with those in adjacent non-neoplastic urothelium. Neurofibromin levels were also decreased in high-grade TCC, suggesting that alterations of NF1 gene expression might be involved in urinary TCC carcinogenesis. Whole genomic analysis performed on 35 stage IV urothelial cancers that had relapsed and progressed after primary surgery and conventional chemotherapy revealed NF1 mutations in two cases (6\%) [149]. Integrated analysis of 131 urothelial carcinomas showed recurrent mutations in 32 genes, with $14 \%$ of tumours having NF1 mutations.

\section{Other malignant tumours}

There are a number of other malignant tumour types that have been found to harbour NF1 alterations including neuroendocrine prostate cancer (24\%), myxofibrosarcomas (10.5\%) and pleomorphic liposarcomas (8\%), pancreatic cancer (11\%), gastric adenocarcinoma (10\%) and rhabdomyosarcoma (7\%) [44, 45]. Somatic NF1 mutations have also been detected in $41-72 \%$ of sporadic MPNSTs, showing that NF1 inactivation plays a major role in the development of this tumour type [96].

\section{General discussion}

Neurofibromatosis type 1 , caused by constitutional inactivating mutations in the tumour suppressor gene $N F 1$, is a neurodegenerative disorder predisposing individuals to both benign and malignant tumours [150-152]. Additionally, somatic mutations of NF1 are also frequent in desmoplastic, cutaneous and mucosal melanoma, high-grade serous ovarian cancer, breast cancer, phaeochromocytomas and paragangliomas, glioblastoma multiforme, myeloid malignancies, neuroblastoma, and colorectal and urinary bladder transitional cell carcinoma (Table 1). Aberrations in neurofibromin result in the dysregulation of the RAS/MAPK pathway leading to unregulated cell growth and proliferation. The related mTOR pathway and other downstream activators and effectors of RAS including PI3K are also involved in cancer $[17,153]$. 
Mutations (chromosomal aberrations, nucleotide substitutions and epigenetic aberrations) in a subset of candidate genes are likely to confer a growth advantage resulting in the development of cancer. Cancer encompasses more than 100 different diseases, the study of which provides insight into both the commonalities and differences between and amongst various types and subtypes of cancer [147]. In order to understand this complex disease and to develop novel targeted therapeutics, it is essential to characterize the somatic mutational spectra in each cancer genome in order to facilitate our understanding of the biological processes underlying the cancer as well as the pathways of evolutionary progression. The availability of the human genome reference sequence enabled the rapid resequencing of cancer genomes, leading to the discovery of many additional cancer genes, revealing for the first time the molecular heterogeneity of cancer genomes and identifying therapeutic targets. To improve the diagnosis and treatment of cancer patients, several large-scale cancer genomics projects, e.g. the TCGA, ICGC, cBioPortal and COSMIC, have been undertaken in recent years [41-44]. These pan-cancer projects have generated highthroughput data which provide valuable opportunities to understand the biology, initiation and progression of human cancers. One caveat, however, is distinguishing artefactual DNA damage from the bona fide mutations that actually occurred in the tumour, given that it has been reported that mutagenic damage accounts for the majority of the erroneous identification of variants with low to moderate (1 to $5 \%$ ) frequency in whole (cancer) genome sequencing studies [154].

Generally, a large number of mutations occur in cancer genomes, such as somatic mutations, CNAs, methylation aberrations and histone modifications. It is critical to distinguish driver mutations and driver genes (which contribute to the progression of cancer from normal to malignant states) from passenger mutations and passenger genes (which accumulate in cells but do not contribute to cancer development). There is a subtle difference between a driver gene and a driver gene mutation. A driver gene harbours driver gene mutations but may also harbour passenger gene mutations. A driver mutation typically confers upon a tumour only a very small growth advantage, which may be as low as a $0.4 \%$ increase in the difference between cell birth and death rates [155]. More recently, Bozic and colleagues have shown that the first, and hence most abundant, passenger mutations are influenced both by the mutation rate and by the death-birth ratio of the cancer cells [156]. It should be appreciated that whilst passenger mutations do not, by definition, exert a strong selective growth advantage, they are not entirely neutral. Indeed, many are deleterious in terms of their effect on cellular proliferation and cancer progression [157, 158]. It should also be appreciated that whilst the damaging effect of a non-synonymous passenger mutation is on average 100 times smaller than the effect of a driver mutation, passengers are 100 times more numerous than drivers [158]. The paucity of drivers in a sea of passenger mutations represents a challenge to identifying the former. This task is made all the more daunting by the possibility that drivers and passengers are not discrete entities but rather lie along a continuum which includes latent driver mutations which 'behave as passengers but coupled with other emerging mutations, drive cancer development and drug resistance' [159].

In 2004, Futreal and colleagues published a 'Census of human cancer genes' which aimed to list all genes that are causally implicated in tumorigenesis. This census has been kept up to date and currently includes 602 entries $[43,160]$. This implies that more than $2 \%$ of all human genes are implicated in cancer. Of these, approximately $90 \%$ have somatic mutations in cancer; $20 \%$ have germline mutations that predispose to cancer; and $10 \%$ harbour both somatic and germline mutations. A second resource, the Network of Cancer Genes (NCG) contains a total of 1053 'cancer genes' whose possible involvement in cancer has been inferred by statistical means [161]. The number of genes recognized as being cancerassociated is likely to increase as new techniques are devised to identify the function of the associated proteins $[162,163]$.

\section{Cooperativity and exclusivity of NF1 somatic mutations}

Mitogen-activated protein kinases (MAPK) and phosphoinositide-3 kinase (PI3K) pathways are key cellular growth regulators. In a normal cell, these control cell growth and survival but are often disrupted in a malignant cell with a deregulated MAPK or PI3K pathway. It is now well recognized that the focus should be upon cellular pathways rather than on individual genes to achieve a full understanding of cancer biology. Therefore, defining driver pathways is an important step to understanding the molecular mechanisms underlying cancer. Previous studies have focussed mainly on identifying the alterations in cancer genomes at the individual gene or single pathway level. However, a great deal of evidence indicates that multiple pathways often function cooperatively in carcinogenesis and other key biological processes. A common and restricted number of driver genes and pathways are probably responsible for most common forms of cancer [40, 147].

In general, mutations of the genes in one pathway usually exhibit mutual exclusivity, because a single mutation is usually enough to disturb one pathway and any further hits in other components of that pathway confer no added selectable advantage. Thus, sporadic tumours with NF1 mutations are mutually exclusive for mutations in 
MAPK kinase 1 (MAP2K1) or NRAS. Strongly activating 'canonical' mutations in oncogenes (for example G12D or G12V mutations in KRAS) can drive cancer formation on their own and are known to be epistatic in relation to other canonical mutations within the same pathway [164]. However, whether there are, for example, 'non-canonical' mutations that weakly activate oncogenes or only partially inactivate tumour suppressor activity and yet can drive cancer formation is less clear. Examination of genomic data from the Cancer Cell Line Encyclopedia (CCLE) and TCGA has indicated that whilst canonical KRAS mutations do not occur with increased frequency in the context of NF1 mutations, non-canonical KRAS mutations certainly do, suggesting that such pairs of mutations might act together to confer a selective advantage in human tumours [164]. Activation of RAS guanine nucleotide exchange factors (RAS-GEFs) was predicted to have similar effects to neurofibromin loss and that non-canonical KRAS mutations co-occur with RAS-GEF mutations in TCGA and CCLE data [164]. Furthermore, increased frequencies of mutations in both NF1 and other RAS pathway activators or effectors have been found which suggests that this principle could apply more broadly to other genes in the RAS network and possibly to other oncogenic signalling pathways [58]. Subsequently, NF1 loss has been described as a key mediator of acquired and intrinsic BRAF inhibitor resistance following a highthroughput short hairpin RNA screening approach [53]. Furthermore, on the basis of analyses of somatic comutation patterns in the TCGA data sets (cBio Portal for Cancer Genomics), 9.6\% of melanomas with NF1 mutations also have mutations in BRAF, NRAS or RAF1 [47]. But, whilst mutant NF1 is known to cooperate with RASopathy genes (RASA2, PTPN11, SOS1, RAF1 and SPRED1) in melanoma and although $N F 1$ is found to be frequently mutated $(25-30 \%)$ in melanomas harbouring wild-type $B R A F$ and NRAS, it is curious that melanoma is not a tumour type associated with NF1 [8, 49-51].

The capacity of NF1 mutations to act both cooperatively and exclusively without $B R A F$ and NRAS mutations in melanoma may be mediated through pathways other than the MAPK pathway. Maertens and colleagues have identified increased activation of the PI3K/AKT/ mTOR pathway in BRAF/NF1 double mutants, and a combinatorial MEK marker and mTOR inhibitor treatment has proven effective in many MEK inhibitorresistant neoplasms [58]. In a glioblastoma animal model, NF1 cooperates with both TP53 and PTEN, but no cooccurrence of NF1 and BRAF mutations is seen [137]. Moreover, whilst simultaneous inactivation of $N f 1$ and expression of $\mathrm{K}-\mathrm{Ras}^{\mathrm{G}}{ }^{\mathrm{G} 2 \mathrm{D}}$ in mouse haematopoietic cells results in AML that was fatal in primary mice within 4 weeks, in ovarian serous carcinomas, cooperation between mutant TP53 and NF1 results in a poor prognosis
[92, 117]. In addition, an association between inactivated NF1 and ZNF423 levels in neuroblastomas has been identified as a putative prognostic marker [130].

It should be appreciated that the same gene can function in completely opposite ways in different cell types. In melanomas harbouring BRAF V600E mutations, a BRAF inhibitor induces remission of the tumour; however, the same drug is ineffective in colorectal cancer cells harbouring identical mutations. This has been attributed to the expression of EGFR which occurs in some colorectal cancers, but not in melanomas [165].

Despite all the cancer genome information available regarding NF1, it remains unclear why NF1 patients are predisposed only to certain types of tumours. Why, for example, are NF1 patients not predisposed to lung tumours given that at least $10 \%$ of all sporadic lung cancers have NF1 mutations $[8,65,72,166]$ ?

\section{NF1 and drug resistance}

The RAS/MAPK pathway, with an important role in cancer biology, is a prime target for anti-cancer agents; however, the presence of an NF1 mutation, resulting in reduced expression of neurofibromin, confers resistance to several therapeutic drugs. Furthermore, NF1-associated drug resistance to RAF and EGFR inhibitors, tamoxifen and retinoic acid, has been observed in melanoma, lung cancers, breast cancers and neuroblastoma, respectively, and melanoma cells with BRAF/NF1 mutations develop resistance to BRAF inhibitors [58, 111, 130, 167]. It is not clear whether the specific nature of the mutations could have exerted an influence on the sensitivity of the drug, as complete inactivation of $N F 1$ has been noted to confer sensitivity to rapamycin in AML [85].

\section{Mutational spectrum}

Large constitutional NF1 deletions, encompassing the NF1 gene and many adjacent genes, occur in $5-10 \%$ of NF1 cases and are often associated with a more severe phenotype including learning disabilities and increased susceptibility to MPNSTs [168, 169]. Intriguingly, such mutations resulting in heterozygous or homozygous loss of NF1 expression are found to occur more often as sporadic events in AML and ovarian carcinoma, based on cBioPortal data [45]. An NF1 microdeletion in combination with an abnormal karyotype is an indicator of poor prognosis in AML; 7.6\% of ovarian serous cystadenocarcinomas, $2.8 \%$ of lung squamous cell carcinomas, $3.3 \%$ of glioblastomas and $1.9 \%$ of phaeochromocytomas/paragangliomas harboured deletions $[45,82,84]$.

NF1 amplification, and presumably increased neurofibromin expression and hence activity, has been identified in many cancers, including breast (17\%), pancreatic $(21.5 \%)$, uterine endometrial $(1.8 \%)$ and neuroendocrine prostate cancer (21.5\%) [45]. 
The pathological significance of sporadic NF1 point mutations, especially putative missense mutations that have been identified in many sporadic tumours, is often unclear. Constitutional NF1 missense mutations represent about $15 \%$ of all NF1 mutations, but their frequency in sporadic tumours ranges widely from 15 to $71 \%[24,25,45,72,106,143,167,170-172]$. The characterization of such missense mutations has yielded new insights into the structure and function of neurofibromin. For example, through analysis of missense mutations, the arginine finger loop of the neurofibromin GRD has been found to be crucial for stabilizing the transition state of the GTPase reaction, and many missense mutations in the GRD have been found to exert a significant, pathological effect on Ras activity levels [36, 173, 174].

\section{Conclusion}

Somatic NF1 mutations are present in tumours associated with NF1 and in a range of sporadic tumours, in different cell types and at various frequencies (Table 1). The frequency and temporal occurrence of somatic mutations and the range of histological types in which they occur therefore imply an important role for neurofibromin function in cancer development and progression. Whilst it is unclear whether the biallelic loss of NF1 is common or if only heterozygous mutations of NF1 contribute to tumour progression in sporadic tumours, mouse cells heterozygous for $N f 1$ mutations show abnormal growth and invasion $[138,175]$.

Somatic NF1 mutations may be critical drivers in multiple cancers as well as contributing to resistance to therapy. The mutational landscape of somatic NF1 mutation should provide new insights into our understanding of the pathophysiology of cancer.

The introduction of a molecular genomics approach to cancer biology represents a major shift in our approach to the diagnosis and treatment of malignancy. The vast amount of genomic data generated over the last 10 years, which continues to be generated, is providing invaluable insights into the complexities of cancer genome structure, function and evolution. With recent advances in sequencing technology and high-throughput drug discovery, the increasing availability of more sophisticated animal models and the application of the state-of-the-art tumour imaging techniques and the diagnosis and treatment of cancer can only improve. The identification of somatic NF1 mutations in such a wide spectrum of tumours, including types not associated with NF1, indicates that neurofibromin is likely to play a key role in cancer, far beyond that evident in the tumour predisposition syndrome NF1.

\section{Abbreviations}

ADC: Adenocarcinoma; AML: Acute myeloid leukaemia; AOCS: The Australian Ovarian Cancer Study; CCLE: Cancer Cell Line Encyclopedia; CMML: Chronic myelomonocytic leukaemia; CNS: Central nervous system; COSMIC: Catalogue of Somatic Mutations in Cancer; HGOSC: High-grade serous ovarian carcinoma; HR: Homologous recombination; ICGC: International Cancer Genome Consortium; JMML: Juvenile myelomonocytic leukaemia; MAPK: Mitogen-activated protein kinases; MPNST: Malignant peripheral nerve sheath tumour;

NF1: Neurofibromatosis type 1; NSCLC: Non-small cell lung cancer; OSC: Ovarian serous carcinoma; PI3K: Phosphoinositide-3 kinase; RAS-GEFs: RAS guanine nucleotide exchange factors; SCLC: Small cell lung cancer; SqCC: Squamous cell lung cancer; T-ALL: T cell acute lymphoblastic Leukaemia; TCC: Urothelial transitional cell carcinoma; TCGA: The Cancer Genome Atlas

\section{Acknowledgements}

Not applicable.

Funding

We thank Sheila and Clive Owen for the financial support.

Availability of data and materials

Not applicable.

Authors' contributions

MU initiated the study, supported by CP, HT, IMF and DNC. All authors contributed to the writing and review of the manuscript. All authors read and approved the final manuscript.

\section{Competing interests}

The authors declare that they have no competing interests.

Consent for publication

Not applicable.

Ethics approval and consent to participate Not applicable.

\section{Publisher's Note}

Springer Nature remains neutral with regard to jurisdictional claims in published maps and institutional affiliations.

Received: 14 May 2017 Accepted: 2 June 2017

Published online: 21 June 2017

\section{References}

1. Bennett E, Thomas N, Upadhyaya M. Neurofibromatosis type 1: its association with the Ras/MAPK pathway syndromes. J Pediatr Neurol. 2009; 7(2):105-15.

2. Cooper DN, Upadhyaya M. The germline mutational spectrum in neurofibromatosis type 1 and genotype-phenotype correlations, Chapter 10 . In: Upadhyaya M, Cooper DN, editors. Neurofibromatosis Type 1, vol. Chapter 10. Berlin: Springer Verlag; 2012. p. 115-34.

3. Huson SM, Compston DA, Clark P, Harper PS. A genetic study of von Recklinghausen neurofibromatosis in south east Wales. I. Prevalence, fitness, mutation rate, and effect of parental transmission on severity. J Med Genet. 1989;26(11):704-11.

4. Lammert M, Friedman JM, Kluwe L, Mautner VF. Prevalence of neurofibromatosis 1 in German children at elementary school enrollment. Arch Dermatol. 2005;141(1):71-4

5. Upadhyaya M, Huson SM, Davies M, Thomas N, Chuzhanova N, Giovannini S, Evans DG, Howard E, Kerr B, Griffiths S, et al. An absence of cutaneous neurofibromas associated with a 3-bp inframe deletion in exon 17 of the NF1 gene (c.2970-2972 delAAT): evidence of a clinically significant NF1 genotype-phenotype correlation. Am J Hum Genet. 2007;80(1):140-51.

6. Upadhyaya M. Genetic basis of tumorigenesis in NF1 malignant peripheral nerve sheath tumors. Front Biosci (Landmark Ed). 2011;16:937-51.

7. Upadhyaya M, Kluwe L, Spurlock G, Monem B, Majounie E, Mantripragada K, Ruggieri M, Chuzhanova N, Evans DG, Ferner R, Thomas N, Guha A, Mautner V. Germline and somatic NF1 gene mutation spectrum in NF1-associated malignant peripheral nerve sheath tumors (MPNSTs). Hum Mutat. 2008;29(1):74-82. 
8. Walker L, Thompson D, Easton D, Ponder B, Ponder M, Frayling I, Baralle D. A prospective study of neurofibromatosis type 1 cancer incidence in the UK. Br J Cancer. 2006;95(2):233-8.

9. Brems H, Beert E, de Ravel T, Legius E. Mechanisms in the pathogenesis of malignant tumours in neurofibromatosis type 1. Lancet Oncol. 2009;10(5):508-15.

10. Knudson Jr AG. Mutation and cancer: statistical study of retinoblastoma. Proc Natl Acad Sci U S A. 1971;68(4):820-3.

11. Viskochil D, Buchberg AM, Xu G, Cawthon RM, Stevens J, Wolff RK, Culver M, Carey JC, Copeland NG, Jenkins NA, et al. Deletions and a translocation interrupt a cloned gene at the neurofibromatosis type 1 locus. Cell. 1990;62(1):187-92.

12. Cichowski K, Jacks T. NF1 tumor suppressor gene function: narrowing the GAP. Cell. 2001;104(4):593-604.

13. McClatchey Al. Neurofibromatosis. Annu Rev Pathol. 2007;2:191-216.

14. Welti S, D'Angelo I, Scheffzek K. Structure and function of neurofibromin. In: Neurofibromatoses. Basel: Karger; 2008:113-28.

15. Scheffzek $K$, Welti S. Pleckstrin homology (PH) like domains-versatile modules in protein-protein interaction platforms. FEBS Lett. 2012;586(17):2662-73.

16. Scheffzek K, Welti S. Neurofibromin: protein domains and functional characteristics. In: Upadhyaya M, Cooper DN, editors. Neurofibromatosis Type 1. Berlin Heidelberg: Springer; 2012. p. 305-26.

17. Johannessen CM, Reczek EE, James MF, Brems H, Legius E, Cichowski K. The NF1 tumor suppressor critically regulates TSC2 and mTOR. Proc Natl Acad Sci U S A. 2005;102(24):8573-8.

18. Shilyansky C, Lee YS, Silva AJ. Molecular and cellular mechanisms of learning disabilities: a focus on NF1. Annu Rev Neurosci. 2010;33:221-43.

19. Hollstein PE, Cichowski K. Identifying the ubiquitin ligase complex that regulates the NF1 tumor suppressor and Ras. Cancer Discov. 2013;3(8):880-93.

20. Peltonen S, Kallionpaa RA, Peltonen J. Neurofibromatosis type 1 (NF1) gene: beyond cafe au lait spots and dermal neurofibromas. Exp Dermatol. 2016. doi:10.1111/exd.13212

21. Gutmann DH, Parada LF, Silva AJ, Ratner N. Neurofibromatosis type 1: modeling CNS dysfunction. J Neurosci. 2012;32(41):14087-93.

22. Neurofibromin (NF1). https://grenada.lumc.nl/LOVD2/mendelian_genes/ home.php?select db=NF1. Accessed Mar 2017

23. Griffiths S, Thompson P, Frayling I, Upadhyaya M. Molecular diagnosis of neurofibromatosis type 1: 2 years experience. Fam Cancer. 2007:6(1):21-34

24. Messiaen LM, Callens T, Mortier G, Beysen D, Vandenbroucke I, Van Roy N, Speleman F, Paepe AD. Exhaustive mutation analysis of the NF1 gene allows identification of $95 \%$ of mutations and reveals a high frequency of unusual splicing defects. Hum Mutat. 2000:15(6):541-55.

25. Messiaen LM, Wimmer K. NF1 Mutational spectrum. In: neurofibromatoses. Kaufmann D, editor. Basel: Karger; 2008:63-77.

26. van Minkelen $R$, van Bever $Y$, Kromosoeto JN, Withagen-Hermans CJ, Nieuwlaat A, Halley DJ, van den Ouweland AM. A clinical and genetic overview of 18 years neurofibromatosis type 1 molecular diagnostics in the Netherlands. Clin Genet. 2014;85(4):318-27.

27. Stenson PD, Mort M, Ball EV, Evans K, Hayden M, Heywood S, Hussain M, Phillips AD, Cooper DN. The Human Gene Mutation Database: towards a comprehensive repository of inherited mutation data for medical research genetic diagnosis and next-generation sequencing studies. Hum Genet. 2017. doi:10.1007/s00439-017-1779-6 [Epub ahead of print]

28. Evans DG, Bowers N, Burkitt-Wright E, Miles E, Garg S, Scott-Kitching V, PenmanSplitt M, Dobbie A, Howard E, Ealing J, et al. Comprehensive RNA analysis of the NF1 gene in classically affected NF1 affected individuals meeting NIH criteria has high sensitivity and mutation negative testing is reassuring in isolated cases with pigmentary features only. EBioMedicine. 2016;7:212-20.

29. Mautner VF, Kluwe L, Friedrich RE, Roehl AC, Bammert S, Hogel J, Spori H, Cooper DN, Kehrer-Sawatzki H. Clinical characterisation of 29 neurofibromatosis type-1 patients with molecularly ascertained 1.4 Mb type-1 NF1 deletions. J Med Genet. 2010:47(9):623-30.

30. Pros E, Gomez C, Martin T, Fabregas P, Serra E, Lazaro C. Nature and mRNA effect of 282 different NF1 point mutations: focus on splicing alterations. Hum Mutat. 2008;29(9):E173-193.

31. Bottillo I, Torrente I, Lanari V, Pinna V, Giustini S, Divona L, De Luca A, Dallapiccola B. Germline mosaicism in neurofibromatosis type 1 due to a paternally derived multi-exon deletion. Am J Med Genet A. 2010;152A(6):1467-73.

32. Colman SD, Rasmussen SA, Ho VT, Abernathy CR, Wallace MR. Somatic mosaicism in a patient with neurofibromatosis type 1. Am J Hum Genet. 1996;58(3):484-90.

33. Lazaro C, Ravella A, Gaona A, Volpini V, Estivill X. Neurofibromatosis type 1 due to germ-line mosaicism in a clinically normal father. N Engl J Med. 1994;331(21):1403-7.
34. Messiaen L, Vogt J, Bengesser K, Fu C, Mikhail F, Serra E, Garcia-Linares C, Cooper DN, Lazaro C, Kehrer-Sawatzki H. Mosaic type-1 NF1 microdeletions as a cause of both generalized and segmental neurofibromatosis type-1 (NF1). Hum Mutat. 2011;32(2):213-9.

35. Wimmer K, Yao S, Claes K, Kehrer-Sawatzki H, Tinschert S, De Raedt T, Legius E, Callens T, Beiglbock H, Maertens $\mathrm{O}$, et al. Spectrum of single- and multiexon NF1 copy number changes in a cohort of 1,100 unselected NF1 patients. Genes Chromosomes Cancer. 2006;45(3):265-76.

36. Thomas L, Richards M, Mort M, Dunlop E, Cooper DN, Upadhyaya M. Assessment of the potential pathogenicity of missense mutations identified in the GTPase-activating protein (GAP)-related domain of the neurofibromatosis type-1 (NF1) gene. Hum Mutat. 2012;33(12):1687-96.

37. Kehrer-Sawatzki H, Vogt J, Mussotter T, Kluwe L, Cooper DN, Mautner VF. Dissecting the clinical phenotype associated with mosaic type-2 NF1 microdeletions. Neurogenetics. 2012;13(3):229-36.

38. Upadhyaya M. Neurofibromatosis type 1: diagnosis and recent advances. Expert Opin Med Diagn. 2010;4(4):307-22.

39. Tidyman WE, Rauen KA. Pathogenetics of the RASopathies. Hum Mol Genet. 2016:25(R2):R123-32

40. Stratton MR, Campbell PJ, Futreal PA. The cancer genome. Nature. 2009; 458(7239):719-24

41. The Cancer Genome Atlas (TCGA). http://cancergenome.nih.gov/. Accessed Sept 2016.

42. International Cancer Genome Consortium (ICGC). http://icgc.org/. Accessed Sept 2016.

43. Catalogue of Somatic Mutations in Cancer (COSMIC). http://cancer.sanger.ac uk/cosmic. Accessed Sept 2016.

44. cBioPortal for Cancer Genomics. http://www.cbioportal.org/. Accessed Sept 2016.

45. Cerami E, Gao J, Dogrusoz U, Gross BE, Sumer SO, Aksoy BA, Jacobsen A, Byrne CJ, Heuer ML, Larsson E, et al. The cBio cancer genomics portal: an open platform for exploring multidimensional cancer genomics data. Cancer Discov. 2012:2(5):401-4

46. Gao J, Aksoy BA, Dogrusoz U, Dresdner G, Gross B, Sumer SO, Sun Y, Jacobsen A, Sinha R, Larsson $E$, et al. Integrative analysis of complex cancer genomics and clinical profiles using the cBioPortal. Sci Signal. 2013;6(269):11.

47. Ratner N, Miller SJ. A RASopathy gene commonly mutated in cancer: the neurofibromatosis type 1 tumour suppressor. Nat Rev Cancer. 2015;15(5): 290-301.

48. Andersen LB, Fountain JW, Gutmann DH, Tarle SA, Glover TW, Dracopoli NC, Housman DE, Collins FS. Mutations in the neurofibromatosis 1 gene in sporadic malignant melanoma cell lines. Nat Genet. 1993;3(2):118-21.

49. Krauthammer M, Kong Y, Bacchiocchi A, Evans P, Pornputtapong N, Wu C, McCusker JP, Ma S, Cheng E, Straub R, et al. Exome sequencing identifies recurrent mutations in NF1 and RASopathy genes in sun-exposed melanomas. Nat Genet. 2015;47(9):996-1002.

50. Krauthammer $\mathrm{M}$, Kong $\mathrm{Y}, \mathrm{Ha} \mathrm{BH}$, Evans $\mathrm{P}$, Bacchiocchi A, McCusker JP, Cheng E, Davis MJ, Goh G, Choi M, et al. Exome sequencing identifies recurrent somatic RAC1 mutations in melanoma. Nat Genet. 2012;44(9):1006-14

51. Hodis E, Watson IR, Kryukov GV, Arold ST, Imielinski M, Theurillat JP, Nickerson E, Auclair D, Li L, Place C, et al. A landscape of driver mutations in melanoma. Cell. 2012:150(2):251-63.

52. Nissan MH, Pratilas CA, Jones AM, Ramirez R, Won H, Liu C, Tiwari S, Kong L, Hanrahan AJ, Yao Z, et al. Loss of NF1 in cutaneous melanoma is associated with RAS activation and MEK dependence. Cancer Res. 2014;74(8):2340-50.

53. Whittaker SR, Theurillat JP, Van Allen E, Wagle N, Hsiao J, Cowley GS, Schadendorf D, Root DE, Garraway LA. A genome-scale RNA interference screen implicates NF1 loss in resistance to RAF inhibition. Cancer Discov. 2013;3(3):350-62.

54. Akbani R, Ng PK, Werner HM, Shahmoradgoli M, Zhang F, Ju Z, Liu W, Yang JY, Yoshihara K, Li J, et al. Corrigendum: a pan-cancer proteomic perspective on The Cancer Genome Atlas. Nat Commun. 2015;6:4852.

55. Akbani R, Ng PK, Werner HM, Shahmoradgoli M, Zhang F, Ju Z, Liu W, Yang JY, Yoshihara K, Li J, et al. A pan-cancer proteomic perspective on The Cancer Genome Atlas. Nat Commun. 2014:5:3887.

56. Hill VK, Gartner JJ, Samuels Y, Goldstein AM. The genetics of melanoma: recent advances. Annu Rev Genomics Hum Genet. 2013;14:257-79.

57. Garnett MJ, Marais R. Guilty as charged: B-RAF is a human oncogene. Cancer Cell. 2004:6(4):313-9.

58. Maertens O, Johnson B, Hollstein P, Frederick DT, Cooper ZA, Messiaen L, Bronson RT, McMahon M, Granter S, Flaherty $K$, et al. Elucidating distinct roles for NF1 in melanomagenesis. Cancer Discov. 2013;3(3):338-49. 
59. Mar VJ, Wong SQ, Li J, Scolyer RA, McLean C, Papenfuss AT, Tothill RW, Kakavand H, Mann GJ, Thompson JF, et al. BRAF/NRAS wild-type melanomas have a high mutation load correlating with histologic and molecular signatures of UV damage. Clin Cancer Res. 2013;19(17):4589-98.

60. Wiesner T, Kiuru M, Scott SN, Arcila M, Halpern AC, Hollmann T, Berger MF, Busam KJ. NF1 mutations are common in desmoplastic melanoma. Am J Surg Pathol. 2015;39(10):1357-62.

61. Shain AH, Yeh I, Kovalyshyn I, Sriharan A, Talevich E, Gagnon A, Dummer R, North J, Pincus $L$, Ruben B, et al. The genetic evolution of melanoma from precursor lesions. N Engl J Med. 2015;373(20):1926-36.

62. Foster WJ, Fuller CE, Perry A, Harbour JW. Status of the NF1 tumor suppressor locus in uveal melanoma. Arch Ophthalmol. 2003;121(9):1311-5.

63. Cosgarea I, Ugurel S, Sucker A, Livingstone E, Zimmer L, Ziemer M, Utikal J, Mohr P, Pfeiffer C, Pfohler C, et al. Targeted next generation sequencing of mucosal melanomas identifies frequent NF1 and RAS mutations. Oncotarget. 2017.

64. Stewart B, Wild CP. World Cancer Report 2014. International Agency for Research on Cancer. Lyons: WHO Press; 2014.

65. Ding L, Getz G, Wheeler DA, Mardis ER, McLellan MD, Cibulskis K, Sougnez C, Greulich H, Muzny DM, Morgan MB, et al. Somatic mutations affect key pathways in lung adenocarcinoma. Nature. 2008;455(7216):1069-75.

66. Imielinski M, Berger AH, Hammerman PS, Hernandez B, Pugh TJ, Hodis E, Cho J, Suh J, Capelletti M, Sivachenko A, et al. Mapping the hallmarks of lung adenocarcinoma with massively parallel sequencing. Cell. 2012;150(6):1107-20.

67. Cancer Genome Atlas Research N. Comprehensive molecular profiling of lung adenocarcinoma. Nature. 2014;511(7511):543-50.

68. Redig AJ, Capelletti M, Dahlberg SE, Sholl LM, Mach S, Fontes C, Shi Y, Chalasani P, Janne PA. Clinical and molecular characteristics of NF1-mutant lung cancer. Clin Cancer Res. 2016;22(13):3148-56.

69. Jemal A, Bray F, Center MM, Ferlay J, Ward E, Forman D. Global cancer statistics. CA Cancer J Clin. 2011;61(2):69-90.

70. Lipson D, Capelletti M, Yelensky R, Otto G, Parker A, Jarosz M, Curran JA, Balasubramanian S, Bloom T, Brennan KW, et al. Identification of new ALK and RET gene fusions from colorectal and lung cancer biopsies. Nat Med. 2012;18(3):382-4.

71. de Bruin EC, Cowell C, Warne PH, Jiang M, Saunders RE, Melnick MA, Gettinger S, Walther Z, Wurtz A, Heynen GJ, et al. Reduced NF1 expression confers resistance to EGFR inhibition in lung cancer. Cancer Discov. 2014;4(5):606-19.

72. Cancer Genome Atlas Research N. Comprehensive genomic characterization of squamous cell lung cancers. Nature. 2012;489(7417):519-25.

73. Dhanasekaran SM, Balbin OA, Chen G, Nadal E, Kalyana-Sundaram S, Pan J, Veeneman B, Cao X, Malik R, Vats P, et al. Transcriptome meta-analysis of lung cancer reveals recurrent aberrations in NRG1 and Hippo pathway genes. Nat Commun. 2014;5:5893.

74. Campbell JD, Alexandrov A, Kim J, Wala J, Berger AH, Pedamallu CS, Shukla SA, Guo G, Brooks AN, Murray BA, et al. Distinct patterns of somatic genome alterations in lung adenocarcinomas and squamous cell carcinomas. Nat Genet. 2016:48(6):607-16.

75. Devarakonda S, Morgensztern D, Govindan R. Genomic alterations in lung adenocarcinoma. Lancet Oncol. 2015;16(7):e342-351.

76. Rudin CM, Durinck S, Stawiski EW, Poirier JT, Modrusan Z, Shames DS, Bergbower EA, Guan Y, Shin J, Guillory J, et al. Comprehensive genomic analysis identifies SOX2 as a frequently amplified gene in small-cell lung cancer. Nat Genet. 2012;44(10):1111-6.

77. Peifer M, Fernandez-Cuesta L, Sos ML, George J, Seidel D, Kasper LH, Plenker $D$, Leenders $F$, Sun $R$, Zander $T$, et al. Integrative genome analyses identify key somatic driver mutations of small-cell lung cancer. Nat Genet. 2012; 44(10):1104-10.

78. Ross JS, Wang K, Elkadi OR, Tarasen A, Foulke L, Sheehan CE, Otto GA, Palmer G, Yelensky R, Lipson D, et al. Next-generation sequencing reveals frequent consistent genomic alterations in small cell undifferentiated lung cancer. J Clin Pathol. 2014;67(9):772-6.

79. Balgobind BV, Van Vlierberghe P, van den Ouweland AM, Beverloo HB, Terlouw-Kromosoeto JN, van Wering ER, Reinhardt D, Horstmann M, Kaspers GJ, Pieters R, et al. Leukemia-associated NF1 inactivation in patients with pediatric T-ALL and AML lacking evidence for neurofibromatosis. Blood. 2008;111(8):4322-8.

80. Fioretos T, Strombeck B, Sandberg T, Johansson B, Billstrom R, Borg A, Nilsson PG, Van Den Berghe $H$, Hagemeijer A, Mitelman F, et al. Isochromosome $17 q$ in blast crisis of chronic myeloid leukemia and in other hematologic malignancies is the result of clustered breakpoints in 17p11 and is not associated with coding TP53 mutations. Blood. 1999;94(1):225-32.
81. Braun BS, Shannon K. Targeting Ras in myeloid leukemias. Clin Cancer Res 2008;14(8):2249-52.

82. Boudry-Labis E, Roche-Lestienne C, Nibourel O, Boissel N, Terre C, Perot C, Eclache V, Gachard N, Tigaud I, Plessis G, et al. Neurofibromatosis-1 gene deletions and mutations in de novo adult acute myeloid leukemia. Am J Hematol. 2013;88(4):306-11.

83. Garcia-Orti L, Cristobal I, Cirauqui C, Guruceaga E, Marcotegui N, Calasanz MJ, Castello-Cros R, Odero MD. Integration of SNP and mRNA arrays with microRNA profiling reveals that MiR-370 is upregulated and targets NF1 in acute myeloid leukemia. PLoS One. 2012;7(10):e47717.

84. Haferlach C, Grossmann V, Kohlmann A, Schindela S, Kern W, Schnittger S, Haferlach T. Deletion of the tumor-suppressor gene NF1 occurs in 5\% of myeloid malignancies and is accompanied by a mutation in the remaining allele in half of the cases. Leukemia. 2012;26(4):834-9.

85. Parkin B, Ouillette $P$, Wang $Y$, Liu Y, Wright W, Roulston D, Purkayastha A, Dressel A, Karp J, Bockenstedt $P$, et al. NF1 inactivation in adult acute myelogenous leukemia. Clin Cancer Res. 2010;16(16):4135-47.

86. Misawa S, Horiike S, Kaneko H, Kashima K. Genetic aberrations in the development and subsequent progression of myelodysplastic syndrome. Leukemia. 1997;11 Suppl 3:533-5.

87. Kolquist KA, Schultz RA, Furrow A, Brown TC, Han JY, Campbell LJ, Wall M, Slovak ML, Shaffer LG, Ballif BC. Microarray-based comparative genomic hybridization of cancer targets reveals novel, recurrent genetic aberrations in the myelodysplastic syndromes. Cancer Genet. 2011;204(11):603-28

88. Kalender Atak Z, De Keersmaecker K, Gianfelici V, Geerdens E, Vandepoel R, Pauwels D, Porcu M, Lahortiga I, Brys V, Dirks WG, et al. High accuracy mutation detection in leukemia on a selected panel of cancer genes. PLoS One. 2012;7(6):e38463.

89. Side L, Taylor B, Cayouette M, Conner E, Thompson P, Luce M, Shannon K. Homozygous inactivation of the NF1 gene in bone marrow cells from children with neurofibromatosis type 1 and malignant myeloid disorders. $\mathrm{N}$ Engl J Med. 1997;336(24):1713-20.

90. Caye A, Strullu M, Guidez F, Cassinat B, Gazal S, Fenneteau O, Lainey E, Nouri K, Nakhaei-Rad S, Dvorsky R, et al. Juvenile myelomonocytic leukemia displays mutations in components of the RAS pathway and the PRC2 network. Nat Genet. 2015;47(11):1334-40.

91. Margueron R, Reinberg D. The Polycomb complex PRC2 and its mark in life. Nature. 2011;469(7330):343-9.

92. Cutts BA, Sjogren AK, Andersson KM, Wahlstrom AM, Karlsson C, Swolin B, Bergo MO. Nf1 deficiency cooperates with oncogenic K-RAS to induce acute myeloid leukemia in mice. Blood. 2009;114(17):3629-32.

93. Abdel-Wahab O, Tefferi A, Levine RL. Role of TET2 and ASXL1 mutations in the pathogenesis of myeloproliferative neoplasms. Hematol Oncol Clin North Am. 2012;26(5):1053-64

94. Abdel-Wahab O, Dey A. The ASXL-BAP1 axis: new factors in myelopoiesis, cancer and epigenetics. Leukemia. 2013;27(1):10-5.

95. De Raedt T, Beert E, Pasmant E, Luscan A, Brems H, Ortonne N, Helin K, Hornick JL, Mautner V, Kehrer-Sawatzki H, et al. PRC2 loss amplifies Rasdriven transcription and confers sensitivity to BRD4-based therapies. Nature. 2014,514(7521):247-51.

96. Lee W, Teckie S, Wiesner T, Ran L, Prieto Granada CN, Lin M, Zhu S, Cao Z, Liang Y, Sboner A, et al. PRC2 is recurrently inactivated through EED or SUZ12 loss in malignant peripheral nerve sheath tumors. Nat Genet. 2014; 46(11):1227-32.

97. Stieglitz E, Taylor-Weiner AN, Chang TY, Gelston LC, Wang YD, Mazor T, Esquivel E, Yu A, Seepo S, Olsen SR, et al. The genomic landscape of juvenile myelomonocytic leukemia. Nat Genet. 2015;47(11):1326-33.

98. Sharif S, Moran A, Huson SM, Iddenden R, Shenton A, Howard E, Evans DG. Women with neurofibromatosis 1 are at a moderately increased risk of developing breast cancer and should be considered for early screening. J Med Genet. 2007:44(8):481-4.

99. Evans DG, O'Hara C, Wilding A, Ingham SL, Howard E, Dawson J, Moran A, Scott-Kitching V, Holt F, Huson SM. Mortality in neurofibromatosis 1: in North West England: an assessment of actuarial survival in a region of the UK since 1989. Eur J Hum Genet. 2011;19(11):1187-91.

100. Madanikia SA, Bergner A, Ye X, Blakeley JO. Increased risk of breast cancer in women with NF1. Am J Med Genet A. 2012;158A(12):3056-60.

101. Sjoblom T, Jones S, Wood LD, Parsons DW, Lin J, Barber TD, Mandelker D, Leary RJ, Ptak J, Silliman N, et al. The consensus coding sequences of human breast and colorectal cancers. Science. 2006;314(5797):268-74. 
102. Stephens PJ, Tarpey PS, Davies H, Van Loo P, Greenman C, Wedge DC, NikZainal S, Martin S, Varela I, Bignell GR, et al. The landscape of cancer genes and mutational processes in breast cancer. Nature. 2012;486(7403):400-4.

103. Ogata H, Sato H, Takatsuka J, De Luca LM. Human breast cancer MDA-MB231 cells fail to express the neurofibromin protein, lack its type I mRNA isoform and show accumulation of P-MAPK and activated Ras. Cancer Lett. 2001;172(2):159-64.

104. Shima N, Alcaraz A, Liachko I, Buske TR, Andrews CA, Munroe RJ, Hartford SA, Tye BK, Schimenti JC. A viable allele of Mcm4 causes chromosome instability and mammary adenocarcinomas in mice. Nat Genet. 2007;39(1):93-8.

105. Wallace MD, Pfefferle AD, Shen L, McNairn AJ, Cerami EG, Fallon BL, Rinaldi VD, Southard TL, Perou CM, Schimenti JC. Comparative oncogenomics implicates the neurofibromin 1 gene (NF1) as a breast cancer driver. Genetics. 2012;192(2):385-96.

106. Cancer Genome Atlas N. Comprehensive molecular portraits of human breast tumours. Nature. 2012;490(7418):61-70.

107. Meric-Bernstam F, Frampton GM, Ferrer-Lozano J, Yelensky R, Perez-Fidalgo JA, Wang Y, Palmer GA, Ross JS, Miller VA, Su X, et al. Concordance of genomic alterations between primary and recurrent breast cancer. Mol Cancer Ther. 2014;13(5):1382-9.

108. Pereira B, Chin SF, Rueda OM, Vollan HK, Provenzano E, Bardwell HA, Pugh M, Jones L, Russell R, Sammut SJ, et al. Erratum: the somatic mutation profiles of 2,433 breast cancers refine their genomic and transcriptomic landscapes. Nat Commun. 2016;7:11908.

109. Pereira B, Chin SF, Rueda OM, Vollan HK, Provenzano E, Bardwell HA, Pugh M, Jones L, Russell R, Sammut SJ, et al. The somatic mutation profiles of 2,433 breast cancers refines their genomic and transcriptomic landscapes. Nat Commun. 2016;7:11479.

110. Cui $X Y$, Guo YJ, Yao HR. Analysis of microRNA in drug-resistant breast cancer cell line MCF-7/ADR. Nan Fang Yi Ke Da Xue Xue Bao. 2008;28(10):1813-5.

111. Mendes-Pereira AM, Sims D, Dexter T, Fenwick K, Assiotis I, Kozarewa I, Mitsopoulos C, Hakas J, Zvelebil M, Lord CJ, et al. Genome-wide functional screen identifies a compendium of genes affecting sensitivity to tamoxifen. Proc Natl Acad Sci U S A. 2012;109(8):2730-5.

112. Ring A, Dowsett M. Mechanisms of tamoxifen resistance. Endocr Relat Cancer. 2004;11(4):643-58.

113. Sangha N, Wu R, Kuick R, Powers S, Mu D, Fiander D, Yuen K, Katabuchi H, Tashiro $H$, Fearon ER, et al. Neurofibromin 1 (NF1) defects are common in human ovarian serous carcinomas and co-occur with TP53 mutations. Neoplasia. 2008;10(12):1362-72. following 1372.

114. Heintz AP, Odicino F, Maisonneuve P, Quinn MA, Benedet JL, Creasman WT, Ngan HY, Pecorelli S, Beller U. Carcinoma of the ovary. FIGO 26th Annual Report on the Results of Treatment in Gynecological Cancer. Int J Gynaecol Obstet. 2006;95 Suppl 1:S161-192.

115. Gorringe KL, George J, Anglesio MS, Ramakrishna M, Etemadmoghadam D, Cowin P, Sridhar A, Williams LH, Boyle SE, Yanaihara N, et al. Copy number analysis identifies novel interactions between genomic loci in ovarian cancer. PLoS One. 2010;5(9):e11408.

116. Cooke SL, Ng CK, Melnyk N, Garcia MJ, Hardcastle T, Temple J, Langdon S, Huntsman D, Brenton JD. Genomic analysis of genetic heterogeneity and evolution in high-grade serous ovarian carcinoma. Oncogene. 2010;29(35):4905-13.

117. Mittempergher L. Genomic characterization of high-grade serous ovarian cancer: dissecting its molecular heterogeneity as a road towards effective therapeutic strategies. Curr Oncol Rep. 2016;18(7):44.

118. Kulkarni-Datar K, Orsulic S, Foster R, Rueda BR. Ovarian tumor initiating cell populations persist following paclitaxel and carboplatin chemotherapy treatment in vivo. Cancer Lett. 2013;339(2):237-46.

119. Koch CA, Vortmeyer AO, Huang SC, Alesci S, Zhuang Z, Pacak K. Genetic aspects of pheochromocytoma. Endocr Regul. 2001;35(1):43-52.

120. Walther MM, Herring J, Enquist E, Keiser HR, Linehan WM. von Recklinghausen's disease and pheochromocytomas. J Urol. 1999;162(5):1582-6.

121. Welander J, Larsson C, Backdahl M, Hareni N, Sivler T, Brauckhoff M, Soderkvist P, Gimm O. Integrative genomics reveals frequent somatic NF1 mutations in sporadic pheochromocytomas. Hum Mol Genet. 2012;21(26):5406-16.

122. Opocher G, Schiavi F. Genetics of pheochromocytomas and paragangliomas. Best Pract Res Clin Endocrinol Metab. 2010;24(6):943-56.

123. Welander J, Soderkvist P, Gimm O. The NF1 gene: a frequent mutational target in sporadic pheochromocytomas and beyond. Endocr Relat Cancer. 2013;20(4):C13-17

124. Burnichon N, Buffet A, Parfait B, Letouze $E$, Laurendeau I, Loriot C, Pasmant E, Abermil N, Valeyrie-Allanore L, Bertherat J, et al. Somatic NF1 inactivation is a frequent event in sporadic pheochromocytoma. Hum Mol Genet. 2012;21(26): 5397-405.

125. Fishbein L, Nathanson KL. Pheochromocytoma and paraganglioma: understanding the complexities of the genetic background. Cancer Genet. 2012;205(1-2):1-11.

126. Galan SR, Kann PH. Genetics and molecular pathogenesis of pheochromocytoma and paraganglioma. Clin Endocrinol (Oxf). 2013;78(2):165-75.

127. Deyell RJ, Attiyeh EF. Advances in the understanding of constitutional and somatic genomic alterations in neuroblastoma. Cancer Genet. 2011;204(3): $113-21$

128. Shojaei-Brosseau T, Chompret A, Abel A, de Vathaire F, Raquin MA, Brugieres L, Feunteun J, Hartmann O, Bonaiti-Pellie C. Genetic epidemiology of neuroblastoma: a study of 426 cases at the Institut Gustave-Roussy in France. Pediatr Blood Cancer. 2004;42(1):99-105.

129. The I, Murthy AE, Hannigan GE, Jacoby LB, Menon AG, Gusella JF, Bernards A. Neurofibromatosis type 1 gene mutations in neuroblastoma. Nat Genet. 1993;3(1):62-6.

130. Holzel M, Huang S, Koster J, Ora I, Lakeman A, Caron H, Nijkamp W, Xie J, Callens T, Asgharzadeh S, et al. NF1 is a tumor suppressor in neuroblastoma that determines retinoic acid response and disease outcome. Cell. 2010;142(2):218-29.

131. Han D, Spengler BA, Ross RA. Increased wild-type N-ras activation by neurofibromin down-regulation increases human neuroblastoma stem cell malignancy. Genes Cancer. 2011;2(11):1034-43.

132. Parsons DW, Jones S, Zhang X, Lin JC, Leary RJ, Angenendt P, Mankoo P, Carter H, Siu IM, Gallia GL, et al. An integrated genomic analysis of human glioblastoma multiforme. Science. 2008;321(5897):1807-12.

133. Louis DN. Molecular pathology of malignant gliomas. Annu Rev Pathol. 2006;1:97-117.

134. Brennan CW, Verhaak RG, McKenna A, Campos B, Noushmehr H, Salama SR, Zheng S, Chakravarty D, Sanborn JZ, Berman SH, et al. The somatic genomic landscape of glioblastoma. Cell. 2013;155(2):462-77.

135. Jones DT, Hutter B, Jager N, Korshunov A, Kool M, Warnatz HJ, Zichner T, Lambert SR, Ryzhova M, Quang DA, et al. Recurrent somatic alterations of FGFR1 and NTRK2 in pilocytic astrocytoma. Nat Genet. 2013;45(8):927-32.

136. Verhaak RG, Hoadley KA, Purdom E, Wang V, Qi Y, Wilkerson MD, Miller CR, Ding L, Golub T, Mesirov JP, et al. Integrated genomic analysis identifies clinically relevant subtypes of glioblastoma characterized by abnormalities in PDGFRA, IDH1, EGFR, and NF1. Cancer Cell. 2010;17(1):98-110.

137. Zhu Y, Guignard F, Zhao D, Liu L, Burns DK, Mason RP, Messing A, Parada LF. Early inactivation of p53 tumor suppressor gene cooperating with NF1 loss induces malignant astrocytoma. Cancer Cell. 2005;8(2):119-30.

138. Gutmann DH, Loehr A, Zhang Y, Kim J, Henkemeyer M, Cashen A. Haploinsufficiency for the neurofibromatosis 1 (NF1) tumor suppressor results in increased astrocyte proliferation. Oncogene. 1999;18(31):4450-9.

139. Wu M, Wallace MR, Muir D. Nf1 haploinsufficiency augments angiogenesis. Oncogene. 2006;25(16):2297-303.

140. Ahlquist T, Bottillo I, Danielsen SA, Meling GI, Rognum TO, Lind GE, Dallapiccola B, Lothe RA. RAS signaling in colorectal carcinomas through alteration of RAS, RAF, NF1, and/or RASSF1A. Neoplasia. 2008;10(7):680-6. 682 p following 686.

141. Cawkwell L, Lewis FA, Quirke P. Frequency of allele loss of DCC, p53, RBI, WT1, NF1, NM23 and APC/MCC in colorectal cancer assayed by fluorescent multiplex polymerase chain reaction. $\mathrm{Br} J$ Cancer. 1994;70(5):813-8.

142. Leggett B, Young J, Buttenshaw R, Thomas L, Young B, Chenevix-Trench G, Searle J, Ward M. Colorectal carcinomas show frequent allelic loss on the long arm of chromosome 17 with evidence for a specific target region. $\mathrm{Br}$ J Cancer. 1995;71(5):1070-3.

143. Cancer Genome Atlas N. Comprehensive molecular characterization of human colon and rectal cancer. Nature. 2012;487(7407):330-7.

144. Giannakis M, Mu XJ, Shukla SA, Qian ZR, Cohen O, Nishihara R, Bahl S, Cao Y, Amin-Mansour A, Yamauchi M, et al. Genomic correlates of immune-cell infiltrates in colorectal carcinoma. Cell Rep. 2016;17(4):1206.

145. Seshagiri S, Stawiski EW, Durinck S, Modrusan Z, Storm EE, Conboy CB, Chaudhuri S, Guan Y, Janakiraman V, Jaiswal BS, et al. Recurrent R-spondin fusions in colon cancer. Nature. 2012;488(7413):660-4.

146. Fearon ER. Molecular genetics of colorectal cancer. Annu Rev Pathol. 2011;6:479-507.

147. Vogelstein B, Papadopoulos N, Velculescu VE, Zhou S, Diaz Jr LA, Kinzler KW. Cancer genome landscapes. Science. 2013;339(6127):1546-58.

148. Aaltonen V, Bostrom PJ, Soderstrom KO, Hirvonen O, Tuukkanen J, Nurmi M, Laato M, Peltonen J. Urinary bladder transitional cell carcinogenesis is associated with down-regulation of NF1 tumor suppressor gene in vivo and in vitro. Am J Pathol. 1999;154(3):755-65. 
149. Ross JS, Wang K, Al-Rohil RN, Nazeer T, Sheehan CE, Otto GA, He J, Palmer G, Yelensky R, Lipson D, et al. Advanced urothelial carcinoma: next-generation sequencing reveals diverse genomic alterations and targets of therapy. Mod Pathol. 2014;27(2):271-80.

150. Bader JL. Neurofibromatosis and cancer. Ann N Y Acad Sci. 1986;486:57-65.

151. Knudson AG. Antioncogenes and human cancer. Proc Natl Acad Sci U S A 1993;90(23):10914-21.

152. Matsui I, Tanimura M, Kobayashi N, Sawada T, Nagahara N, Akatsuka J. Neurofibromatosis type 1 and childhood cancer. Cancer. 1993;72(9):2746-54.

153. Wullschleger S, Loewith R, Hall MN. TOR signaling in growth and metabolism. Cell. 2006;124(3):471-84.

154. Chen L, Liu P, Evans Jr TC, Ettwiller LM. DNA damage is a pervasive cause of sequencing errors, directly confounding variant identification. Science. 2017; 355(6326):752-6.

155. Bozic I, Antal T, Ohtsuki H, Carter H, Kim D, Chen S, Karchin R, Kinzler KW, Vogelstein B, Nowak MA. Accumulation of driver and passenger mutations during tumor progression. Proc Natl Acad Sci U S A. 2010;107(43):18545-50.

156. Bozic I, Gerold JM, Nowak MA. Quantifying clonal and subclonal passenger mutations in cancer evolution. PLoS Comput Biol. 2016;12(2):e1004731.

157. McFarland CD, Korolev KS, Kryukov GV, Sunyaev SR, Mirny LA. Impact of deleterious passenger mutations on cancer progression. Proc Natl Acad Sci U S A. 2013;110(8):2910-5.

158. McFarland CD, Mirny LA, Korolev KS. Tug-of-war between driver and passenger mutations in cancer and other adaptive processes. Proc Natl Acad Sci U S A. 2014;111(42):15138-43.

159. Nussinov R, Tsai CJ. 'Latent drivers' expand the cancer mutational landscape. Curr Opin Struct Biol. 2015;32:25-32.

160. Futreal PA, Coin L, Marshall M, Down T, Hubbard T, Wooster R, Rahman N, Stratton MR. A census of human cancer genes. Nat Rev Cancer. 2004;4(3): 177-83.

161. Network of Cancer Genes (NCG). http://ncg.kcl.ac.uk/. Accessed Sept 2016.

162. Lawrence MS, Stojanov P, Mermel CH, Robinson JT, Garraway LA, Golub TR, Meyerson M, Gabriel SB, Lander ES, Getz G. Discovery and saturation analysis of cancer genes across 21 tumour types. Nature. 2014;505(7484):495-501.

163. Lawrence MS, Stojanov P, Polak P, Kryukov GV, Cibulskis K, Sivachenko A, Carter SL, Stewart C, Mermel CH, Roberts SA, et al. Mutational heterogeneity in cancer and the search for new cancer-associated genes. Nature. 2013; 499(7457):214-8. doi:10.1038/nature12213.

164. Seton-Rogers S. Oncogenes: one of these things is not like the others. Nat Rev Cancer. 2016;16(1):5.

165. Prahallad A, Sun C, Huang S, Di Nicolantonio F, Salazar R, Zecchin D, Beijersbergen RL, Bardelli A, Bernards R. Unresponsiveness of colon cancer to BRAF(V600E) inhibition through feedback activation of EGFR. Nature. 2012;483(7387):100-3.

166. Furukawa K, Yanai N, Fujita M, Harada Y. Novel mutations of neurofibromatosis type 1 gene in small cell lung cancers. Surg Today. 2003;33(5):323-7.

167. Cancer Genome Atlas Research N. Comprehensive molecular characterization of urothelial bladder carcinoma. Nature. 2014;507(7492):315-22.

168. De Raedt T, Brems H, Wolkenstein P, Vidaud D, Pilotti S, Perrone F, Mautner V, Frahm S, Sciot R, Legius E. Elevated risk for MPNST in NF1 microdeletion patients. Am J Hum Genet. 2003;72(5):1288-92.

169. Pasmant E, Sabbagh A, Spurlock G, Laurendeau I, Grillo E, Hamel MJ, Martin L, Barbarot S, Leheup B, Rodriguez D, et al. NF1 microdeletions in neurofibromatosis type 1: from genotype to phenotype. Hum Mutat. 2010; 31(6):E1506-1518

170. Cancer Genome Atlas Research N. Integrated genomic analyses of ovarian carcinoma. Nature. 2011:474(7353):609-15.

171. Cancer Genome Atlas Research N. Comprehensive genomic characterization defines human glioblastoma genes and core pathways. Nature. 2008; 455(7216):1061-8.

172. Messiaen L, Yao S, Brems H, Callens T, Sathienkijkanchai A, Denayer E, Spencer E, Arn P, Babovic-Vuksanovic D, Bay C, et al. Clinical and mutational spectrum of neurofibromatosis type 1-like syndrome. JAMA. 2009;302(19):2111-8.

173. Ahmadian MR, Kiel C, Stege P, Scheffzek K. Structural fingerprints of the RasGTPase activating proteins neurofibromin and p120GAP. J Mol Biol. 2003; 329(4):699-710.

174. Ahmadian MR, Wiesmuller L, Lautwein A, Bischoff FR, Wittinghofer A. Structural differences in the minimal catalytic domains of the GTPase-activating proteins p120GAP and neurofibromin. J Biol Chem. 1996;271(27):16409-15.
175. Ding H, Shannon P, Lau N, Wu X, Roncari L, Baldwin RL, Takebayashi H, Nagy A, Gutmann DH, Guha A. Oligodendrogliomas result from the expression of an activated mutant epidermal growth factor receptor in a RAS transgenic mouse astrocytoma model. Cancer Res. 2003;63(5):1106-13.

176. Kan Z, Jaiswal BS, Stinson J, Janakiraman V, Bhatt D, Stern HM, Yue P, Haverty PM, Bourgon R, Zheng J, et al. Diverse somatic mutation patterns and pathway alterations in human cancers. Nature. 2010;466(7308):869-73.

177. Kandoth C, McLellan MD, Vandin F, Ye K, Niu B, Lu C, Xie M, Zhang Q, McMichael JF, Wyczalkowski MA, et al. Mutational landscape and significance across 12 major cancer types. Nature. 2013;502(7471):333-9.

178. Bashashati A, Ha G, Tone A, Ding J, Prentice LM, Roth A, Rosner J, Shumansky K, Kalloger S, Senz J, et al. Distinct evolutionary trajectories of primary high-grade serous ovarian cancers revealed through spatial mutational profiling. J Pathol. 2013;231(1):21-34.

179. Kanchi KL, Johnson KJ, Lu C, McLellan MD, Leiserson MD, Wendl MC, Zhang Q, Koboldt DC, Xie M, Kandoth C, et al. Integrated analysis of germline and somatic variants in ovarian cancer. Nat Commun. 2014:5:3156.

180. Ross JS, Ali SM, Wang K, Palmer G, Yelensky R, Lipson D, Miller VA, Zajchowski D, Shawver LK, Stephens PJ. Comprehensive genomic profiling of epithelial ovarian cancer by next generation sequencing-based diagnostic assay reveals new routes to targeted therapies. Gynecol Oncol. 2013;130(3):554-9.

\section{Submit your next manuscript to BioMed Central and we will help you at every step:}

- We accept pre-submission inquiries

- Our selector tool helps you to find the most relevant journal

- We provide round the clock customer support

- Convenient online submission

- Thorough peer review

- Inclusion in PubMed and all major indexing services

- Maximum visibility for your research

Submit your manuscript at www.biomedcentral.com/submit
) Biomed Central 